\title{
Arte Rupestre y Espacios de Memoria: Las Representaciones del Sitio Confluencia (Antofagasta de la Sierra, Catamarca, Argentina)
}

\author{
Rock Art and Spaces of Memory: The Depictions of Confluencia \\ Site (Antofagasta de la Sierra, Catamarca, Argentina)
}

Alvaro Martel ${ }^{\mathrm{I}}$, Silvina Rodríguez Curletto ${ }^{\mathrm{I}}$ y Ezequiel Del BeL ${ }^{\mathrm{II}}$

\begin{abstract}
RESUMEN
Nuestro trabajo aborda la continuidad de la producción rupestre como uno de los tantos mecanismos que permitieron la construcción de memoria social de las comunidades puneñas a lo largo de un proceso de larga duración. Para tal fin, analizamos la secuencia de producción de las manifestaciones rupestres del sitio Confluencia, Antofagasta de la Sierra, Catamarca, Argentina. Dicha secuencia, que representa distintos periodos de la arqueología local y regional (ca. $5500 \mathrm{AP}$ al contacto hispanoindigena), fue llevada a cabo siguiendo una metodología deconstructiva de forma tal que nos permitiera identificar los modos en que se fueron articulando, a través del tiempo, las diversas representaciones que terminaron conformando el conjunto rupestre final. De tal forma, se pudo definir que en la continuidad expresada en las sucesivas producciones rupestresse manifestaba, también, la forma en que los distintos agentes sociales se fueron relacionando con la alteridad que proponian las representaciones preexistentes, ya sea incorporando lo previo al nuevo discurso, o bien, excluyéndolo del mismo.
\end{abstract}

Palabras clave: arte rupestre, memoria, procesos sociales, Puna de Catamarca.

\begin{abstract}
Our work addresses the continuity of rock art production as one of the many mechanisms that allowed the construction of social memory of the Puna communities over a long term process. With this purpose, we analyze the sequence of rock art production of Confluencia site, Antofagasta de la Sierra, Catamarca, Argentina. This sequence, representing different periods of local and regional archeology (from ca. 5500 BP to the Spanish-Native contact period) was carried out using a deconstructive approach in a way that allowed us to identify the modes in which the depictions were articulated through the time, and ended up shaping the final rock art assemblage. Finally, we could say that the continuity expressed in the successive rock art productions shows the way that different social agents get related with the otherness that the preexistent depictions propose, by including the previous into the new discourse or by excluding it.
\end{abstract}

Key words: rock art, memory, social processes, Puna of Catamarca.

\footnotetext{
i Instituto de Arqueología y Museo, Universidad Nacional de Tucumán e Instituto Superior de Estudios Sociales, CONICET/UNT. San Martín 1545, (4000) San Miguel de Tucumán, Argentina. Correo-e: alvaromartel@arnet.com.ar y silvina.curletto@gmail.com

ii Instituto de Arqueología y Museo, Universidad Nacional de Tucumán. San Martín 1545, (4000) San Miguel de Tucumán, Argentina. Correo-e: ezequieldelbel@gmail.com

Recibido: Septiembre 2011 Revisado: Enero 2012 Aceptado: Febrero 2012
} 


\section{INTRODUCCIÓN}

Desde la década del 80, las investigaciones arqueológicas sistemáticas que se realizan en la microrregión de Antofagasta de la Sierra (en adelante ANS), Puna meridional argentina, han revelado la continuidad de la ocupación humana durante los últimos 10.000 años (Aschero 2010). Entre la evidencia recuperada y registrada, se encuentran numerosos sitios con arte rupestre cuyos paneles, por lo general, muestran diversas representaciones - pintadas y/o grabadas- asignadas a los diferentes periodos arqueológicos definidos para la microrregión. En este sentido, el sitio arqueológico Confluencia comprende uno de los casos más importantes para ANS (Aschero 2007, Aschero et al. 2009, Podestá y Olivera 2006, Martel 2010, entre otros), desplegando en sus casi $100 \mathrm{~m}$ de frente numerosos paneles donde se ejecutaron cientos de motivos que nos permiten reconocer una continuidad en la producción de arte rupestre desde el periodo Arcaico hasta el contacto con los europeos.

En este trabajo abordamos el análisis puntual de uno de los paneles de Confluencia, correspondiente a lo que Aschero (2006) definiera como unidad topográfica E1. Este panel contiene representaciones asignadas a modalidades estilísticas ${ }^{1}$ del Arcaico, Formativo, Tardío, Inca y, también, de momentos históricos. A partir de la consideración de superposiciones de motivos, diferencias en la tonalidad de las pátinas y pigmentos, comparaciones estilísticas y uso del espacio plástico, pudimos definir la secuencia de ejecución de las representaciones que llevó a la configuración que en la actualidad observamos en el panel. Pensamos que tal configuración no es casual, sino el resultado de diversos procesos socioculturales donde los distintos actores, productores de las representaciones, se relacionaron con las manifestaciones rupestres precedentes de forma particular, incorporando, negando o resignificando tales imágenes en su propio discurso. Es en este sentido que proponemos un abordaje deconstructivo del conjunto rupestre, como una herramienta analítica que nos permita comprender la configuración del mismo como resultado de un proceso continuo de creación y no como la sumatoria de eventos independientes.

La propuesta de un abordaje deconstructivo del conjunto de representaciones de este panel particular implica, por un lado, la consideración de la variable tiempo como una guía en el desarrollo del análisis rupestre y, por otro, la constante soporte como un marco donde las sucesivas producciones rupestres fueron restringiendo la disponibilidad del espacio 
plástico, generando cierto tipo de relaciones entre las nuevas ejecuciones y la alteridad que proponían la producciones más antiguas.

Tal como destaca Troncoso (2005), el arte rupestre es una materialidad propia a su formación sociocultural, es decir, comprende uno de los tantos objetos por medio del cual los individuos y su comunidad se constituyen socialmente (Preucel 2006). Pero, en la perspectiva temporal que planteamos, podríamos decir que las representaciones rupestres anteriores, al tratarse de un objeto producido por otros, con significados - posiblemente- no disponibles, no habría influido en la nueva producción rupestre. Sin embargo, al mantenernos en esta posición, terminaríamos alejándonos de la posibilidad de aceptar la capacidad que tendrían esas representaciones preexistentes, en tanto objetos, de modificar o afectar en algún sentido la toma de decisiones de un nuevo ejecutor. Es decir, creemos que es posible reconocer cierta agencia de las producciones rupestres previas sobre las elecciones -técnicas y posiblemente iconográficas- realizadas por los individuos que plasmaron allí las nuevas representaciones. Lo anterior, desde una perspectiva peirciana, podría definirse como sus aspectos pragmáticos, es decir, las consecuencias prácticas de esos signos preexistentes, de esas representaciones anteriores sobre las sucesivas ejecuciones rupestres.

Una forma de acercarnos a las consecuencias prácticas de esas configuraciones rupestres preexistentes, es a partir de la consideración del arte rupestre como proceso (Troncoso 2002), aspecto que destaca el activo rol de esta materialidad como medio para la construcción social de la realidad. En este sentido, y siguiendo al autor citado, la producción rupestre se desempeña como una herramienta o estrategia que permite legitimar y justificar situaciones sociales, como así también, construir espacios sociales donde se expresa una forma de entender el mundo. Teniendo en cuenta estas características, podríamos decir que otra de las propiedades intrínsecas del arte rupestre es su potencial en la construcción de la memoria social. Al respecto, Armstrong (2010:20) plantea que,

“... adentrarse en fenómenos sociales tales como la construcción de la memoria colectiva y la transmisión de ésta, parece necesario si lo que se pretende es comprender la forma en que el arte rupestre, en tanto construcción monumental, permite la conservación de determinadas ideas y principios, a la vez que establece una relación indirecta entre poblaciones que no tuvieron necesariamente contacto entre si, basado, fundamentalmente, en la opción cultural de reocupar o no un espacio que evidencia una intervención anterior". 
En casos tales como el que aquí se analizará, la coexistencia de representaciones de diversos periodos al interior de un mismo panel, nos advierte sobre la necesidad de abordar las configuraciones rupestres en términos del tipo de relación que los diferentes ejecutores establecieron entre los nuevos grabados y los anteriores, relación que a partir de distintas estrategias-inclusión/apropiación, exclusión/negación-sustentará el discurso propuesto en un nuevo marco de inteligibilidad. Así, como recientemente destacaran Mills y Walker (2008), en los últimos años se ha puesto especial interés en el rol que desempeńa la interacción entre gente y objetos en la construcción y transmisión de la memoria social. En tal proceso, lo anterior, lo preexistente cobra singular importancia ya que comprenderá una base de materialidad sobre la cual socializarán grupos futuros, transformándola y reviviéndola (Gosden 1994).

\section{El arte Rupestre de ANTOFagasta de la SIERra. De CAZAdores TARDÍOS A EXTIRPADORES DE IDOLATRÍAS}

El arte rupestre de los cazadores-recolectores en la Puna Argentina se caracterizó desde principios del Holoceno por motivos geométricos no figurativos simples. Sin embargo, hacia el 3500 a.C., además de los motivos geométricos simples se agregan en ANS figuras de circunferencias o circunferencias concéntricas con apéndices inferiores junto con representaciones de figuras humanas, camélidos, felinos y aves, aunque éstos últimos en proporciones mínimas (Aschero 1999). Siguiendo al autor citado, el arte rupestre de ANS se asocia a espacios domésticos y vinculados con buenos recursos de caza y recolección, por lo que la funcionalidad posible de las representaciones se relacionaría con la denotación de espacios de retorno previsto, siendo factible que el arte rupestre este funcionando como una marca territorial.

De este modo, a partir del arte rupestre y de otro tipo de evidencias como enterratorios y ofrendas, se plantea que en ANS se produjo un incremento en la presencia de marcas territoriales hacia el 1.500-1000 a.C., producto de un proceso de regionalización asociado al surgimiento de territorios fijos que tiene su correlato en la existencia de la movilidad reducida (Aschero y Hocsman 2011). En ANS existen una serie importante de contextos arqueológicos que habrían tenido una función en la esfera de lo ritual, tal vez a manera de ofrendas (Olivera et al. 2003, Hocsman 2006); y en consonancia con esto se propone, para el lapso 1500-500 a.C., una estrategia de control social a través de un culto a la fertilidad de los 
camélidos silvestres y domésticos, en base a la aparición de ciertos íconos en emplazamientos particulares y a lo discreto de su localización espacial (Aschero 2006, 2007).

Respecto al periodo Formativo (ca. 500 a.C. - 900 d.C.), distintos investigadores han coincidido en las características socioculturales generales de los grupos que habitaron ANS a lo largo de este lapso, como así también en sus estrategias de subsistencia (Olivera 1992, Olivera y Podestá 1993, Aschero 1996, Escola 2000, López Campeny 2009,entre otros), siendo las tres principales: i) grupos con una economía de subsistencia tipo mixta, principalmente pastoril pero con cierta dependencia de los recursos de caza y recolección y una incipiente actividad agrícola, donde la familia representó la unidad principal de trabajo y producción; ii) diversificación de las actividades productivas que, a su vez, involucró la explotación de los recursos presentes a distintas alturas y iii) un patrón de asentamiento comprendido por bases residenciales en fondo de cuenca y sectores intermedios de los principales cursos de agua, y puestos temporarios de caza/pastoreo ubicados en los sectores más altos.

Resumiendo, podríamos decir que la vida durante el Formativo, en la Puna meridional, implicó el uso y explotación de diversos espacios y recursos, combinando distintas prácticas socioeconómicas. Ahora, teniendo en cuenta la evidencia recuperada en los distintos sitios que componen ese sistema de asentamiento y de uso de los diversos espacios productivos, observamos que en la mayoría de los casos el arte rupestre representa otra de las materialidades asociadas a los contextos estudiados. Sobre la base de esta información se propuso que la densidad de sitios con arte rupestre en determinados sectores de la microrregión de ANS estaría en una relación de directa proporcionalidad a la demanda de los recursos presentes en cada uno de esos sectores. La mayor profusión de manifestaciones rupestres en espacios que concentran determinados recursos, habría actuado como un medio para la minimización de conflictos o tensiones sociales entre los grupos que pretendían el acceso a tales espacios y sus recursos. En este caso hemos detectado algunas situaciones particulares en lo que respecta a la temática del arte rupestre, por ejemplo, que existen más representaciones de enfrentamientos -o luchas- en los sitios emplazados en los sectores que concentran mayor cantidad de recursos, siendo éstas casi inexistentes en los sectores menos productivos (Martel 2006). Otras representaciones, de posible carácter emblemático, también tendrían una distribución espacial similar a las escenas de enfrentamientos, tal es el caso de los rectángulos con diseńos geométricos internos - cartuchos- a los que se ha interpretado como 
diacríticos sociales de grupos o linajes particulares, debido a su asociación directa a enterratorios, unidades de habitación, caminos y cursos de agua permanente, entre otros rasgos significativos del emplazamiento (Aschero et al. 2006).

Las investigaciones arqueológicas sobre el período Tardío ( $c a$. 900 d.C. - 1480 d.C.) en la Puna meridional, han comenzado a generar información significativa acerca de los cambios producidos en el uso de espacio y sus recursos. Aún así, debemos reconocer que tales investigaciones se encuentran en una fase temprana de su desarrollo, es decir, los datos que se poseen sobre este lapso son cuantitativamente menores a los disponibles para el Formativo.

Las investigaciones que se vienen desarrollando localmente (sitios Bajo el Coypar, Campo Cortaderas, Qda. de Petra, La Alumbrera, entre otros), han permitido la elaboración de un primer modelo explicativo sobre los cambios y continuidades socioeconómicas en la microrregión de ANS (ver Olivera y Vigliani 2000-2002, Olivera et al. 2003-2005, Olivera et al. 2008, Podestá y Olivera 2006). Algunas de las conclusiones presentadas, podrían resumirse en seis puntos: i) mayor aprovechamiento del espacio productivo de fondo de cuenca, en relación directa con el nuevo desarrollo de tecnologías agrícolas y el mayor peso de la agricultura en la economía de estos grupos; ii) una paulatina modificación de la organización social y política de los grupos habría llevado a una mayor concentración y burocratización del poder; iii) un incremento poblacional que estaría viviendo la región, llevaría a un patrón concentrado de asentamiento, sobre todo en los sectores de pedemonte del fondo de cuenca; iv) continuidad del pastoreo y la caza en las quebradas de altura; v) mayor vínculo social, económico y político con los grupos valliserranos de Belén, Hualfín, Abaucán y vi) una posible consolidación del poder de control, por parte de las élites, sobre el intercambio de bienes a larga distancia a través del tráfico caravanero y la posible institucionalización de esta estrategia de interacción socioeconómica, dentro de la estructura política de las sociedades tardías (Aschero 2000).

La información obtenida desde los estudios del arte rupestre del Tardío, en esta área, permitió definir cómo ese cambio ocurrido en la transición desde el Formativo al Tardío, también afectó al subsistema simbólico e ideológico (Aschero 1996, Martel 2006). Durante este período, la producción de arte rupestre adopta una serie de pautas representacionales que habrían alcanzado a gran parte de los Andes Centro Sur, esto es, una estandarización en los patrones de diseño de determinados motivos -sobre 
todo para las representaciones de camélidos y algunas figuras antropomorfasy una menor variabilidad en los temas representados ${ }^{2}$ (Aschero 2000). Sin embargo, creemos que el cambio más relevante se da en términos de los espacios escogidos para la ejecución del arte rupestre, ya que se comienzan a significar nuevos espacios y, en algunos casos particulares, se reutilizan paneles con representaciones anteriores, muchas veces superponiendo los nuevos motivos a los ya existentes.

Dentro de este proceso de estandarización del arte rupestre, cabe resaltar el rol del motivo escutiforme y del antropomorfo $\mathrm{T}^{3}$ por dos razones fundamentales: primero, porque a diferencia del período anterior, estos motivos pasan a conformar gran parte de las representaciones antropomorfas, no sólo en ANS, sino en gran parte del noroeste argentino; segundo, que estos motivos se van a emplazar -en casi todos los casos- en sitios con representaciones rupestres de periodos anteriores ¿Qué podría implicar este hecho? En primer lugar, que se tratan de motivos-íconos ${ }^{4}$ que, siguiendo la tesis de Montt y Pimentel (2009), representarían la personificación de las hachas y/o cuchillos de finales del periodo Tardío, artefactos que habrían tenido una alta densidad significativa, posiblemente vinculados a la ejecución de determinados rituales o a individuos con poder; de allí, la antropomorfización de los mismos conformándose en verdaderos legisignos icónicos (Martel y Giraudo 2011), en la medida que estos signos muestran "la forma de determinadas relaciones ya normadas en determinado momento de determinada sociedad” (Magariños de Morentín 2008:224).

Por su parte, siguiendo a Donnan (1975), consideramos que el escutiforme y el antropomorfo $\mathrm{T}$, constituirían lo que el autor citado denomina tema figurativo, es decir, la representación sintética de una unidad narrativa más amplia, que remite a una cierta cantidad de información definida por los atributos gráficos presentes en tal representación. Para el caso del motivo camélido -otra figura estandarizada- los criterios de selección de los emplazamientos y soportes para su representación, serían menos restrictos o menos pautados que para el escutiforme o el antropomorfo T. El análisis de la distribución espacial del arte rupestre de este momento y de los temas representados en cada espacio, permitió establecer diferencias significativas respecto del arte rupestre del periodo anterior; diferencias que apuntan hacia un proceso de reconfiguración de un paisaje que ordenará y jerarquizará las nuevas prácticas sociales establecidas por los grupos de poder o autoridad (Martel 2010). 
Lallegadadel Inkaala región, si bien conllevó unafuertereestructuración sociopolítica, pareciera no haber modificado sustancialmente la forma de aprovechar determinados espacios. Es decir, el proceso de intensificación de la producción agrícola y habitación en los sectores de fondo de cuenca, habría continuado la tendencia ya definida en el periodo Tardío (Vigliani 2004). Sin embargo, aún cuando se trata de un periodo todavía poco estudiado en ANS (Raffino y Cigliano 1973, Olivera 1991, Olivera et al. 2003-2005, Elías 2007), las propuestas de Vigliani (2004) son sumamente interesantes respecto de las estrategias implementadas por el Inka para la apropiación, ocupación y dominio de este sector de la Puna argentina. Desde una perspectiva de los paisajes sociales, la investigadora citada resalta la importancia de la intervención material (arquitectura -habitacional y ritual-, caminería y, en menor medida, arte rupestre), por parte del inkario, en los espacios de mayor interacción social de la población local, como argumento para la resignificación del paisaje al servicio del nuevo orden social, político y económico.

En acuerdo con los postulados generales para la producción de arte rupestre durante este periodo (Olivera y Podestá 1993, Aschero 2000, Hernández Llosas 2001, Podestá y Olivera 2006, entre otros), Vigliani sostiene que la producción de esta materialidad particular se reduce significativamente, acotándose principalmente a la ejecución de maquetas agrícolas y a determinadas figuras de camélidos esquemáticos lineales (camélidos patrón H3, en la clasificación de Aschero 2000).

El conocimiento actual sobre la producción de representaciones rupestres, en el área que nos ocupa, en contexto del contacto hispanoindígena y periodo Colonial, es aún menor que para el periodo Inka. En ANS estas representaciones se incluyen en la modalidad estilística Jinetes (Aschero 1999) y comprenden grabados y pinturas que se realizan, generalmente, en los mismos paneles donde se encuentran manifestaciones rupestres anteriores, entre las que destaca la figura ecuestre la que a veces se representa portando un cetro o lanza. Dentro de las representaciones de este periodo ubicamos también los motivos de cruces cristianas (ejes asimétricos), asociadas generalmente a prácticas de extirpación de idolatrías ocurridas durante la Colonia. Tal como se plantea para el periodo Inka, se da la posibilidad de producciones rupestres de tradiciones locales (jinetes) que conservan algunas normas de ejecución (técnicas, elección de emplazamientos, proporciones en la construcción de la figura equina que recuerdan a la de la llama, etc.) y otras (cruces, templos, signos heráldicos, etc.) que tendrían por autores a funcionarios de la Iglesia y la Corona (Gallardo et al. 1990, Fernández 
Distel 1992, Hernández Llosas 2001, Martínez 2005, Arenas y Martínez 2009, entre otros) y que se darían en el marco de disposiciones y normativas implementadas desde España.

\section{SECUENCIA DE PRODUCCIÓN DEL ARTE RUPESTRE DE CONFLUENCIA}

El sitio Confluencia (S 26002'40,75”; O 67025’04,83”; 3380 msnm) se emplaza en el extremo sur del depósito ignimbrítico que hace esquina en la unión del río Calalaste con el Punilla (Figura 1), muy próximo al actual pueblo de Antofagasta de la Sierra (Catamarca, Puna meridional argentina). Sus altos y verticales farallones constituyen el soporte de numerosos grabados y restos de pinturas, correspondientes a los distintos períodos arqueológicos mencionados. Sin embargo, son las representaciones tardías las de mayor preponderancia. El total del conjunto rupestre se distribuye en nueve unidades topográficas (UT A a I), sobre un frente de $82,40 \mathrm{~m}$, con una orientación Este predominante (Aschero 2006). Adosados a estos farallones se encuentran varios corrales actuales, en dos de los cuales se efectuaron excavaciones sin detectarse ocupaciones prehispánicas (Martel 2010).

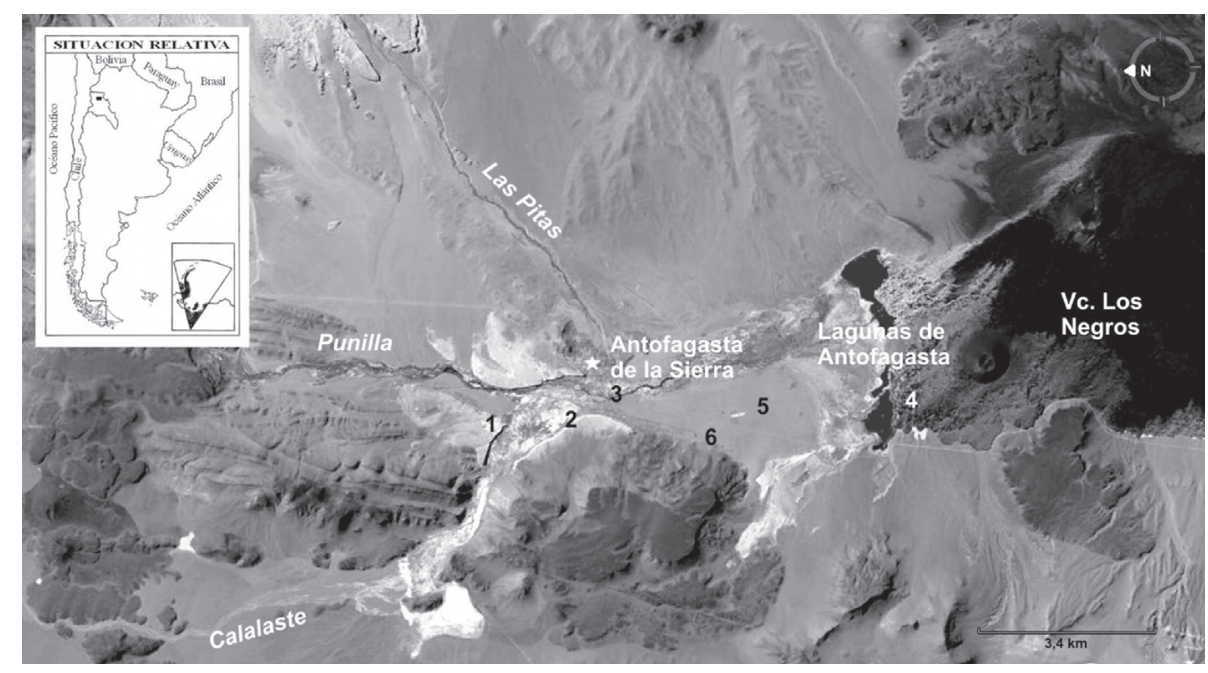

Figura 1: Sector Fondo de cuenca de la microrregión de Antofagasta de la Sierra. Se muestran algunos de los sitios mencionados en este trabajo: 1-Confluencia, 2-Derrumbes, 3-La Torre, 4-La Alumbrera, 5-Bajo el Coypar, 6-Coyparcito.

Figure 1: Low basin of Antofagasta de la Sierra. Sites mentioned in this work: 1-Confluencia, 2-Derrumbes, 3-La Torre, 4-La Alumbrera, 5-Bajo el Coypar, 6-Coyparcito. 
Como dijimos anteriormente, nuestro análisis se focalizó en la UT E1, la cual tiene una superficie de 19,25 $\mathrm{m}^{2}$ (3,5 $\mathrm{m}$ de altura por 5,5 $\mathrm{m}$ de ancho), encontrándose los límites superior e inferior de la misma a unos $6 \mathrm{~m}$ y 2,5 $\mathrm{m}$, sobre el nivel actual del terreno. Pueden sorprender estas medidas, ya que las representaciones quedarían fuera del campo manual de un operador de pie; sin embargo, la presencia de dos grandes bloques (de 3,5 m y $4 \mathrm{~m}$ de altura, respectivamente) que apoyan sobre todo el ancho de la UT, generan una cornisa -más o menos amplia- que actuó como apoyo o estrado de los ejecutores (Figura 2).

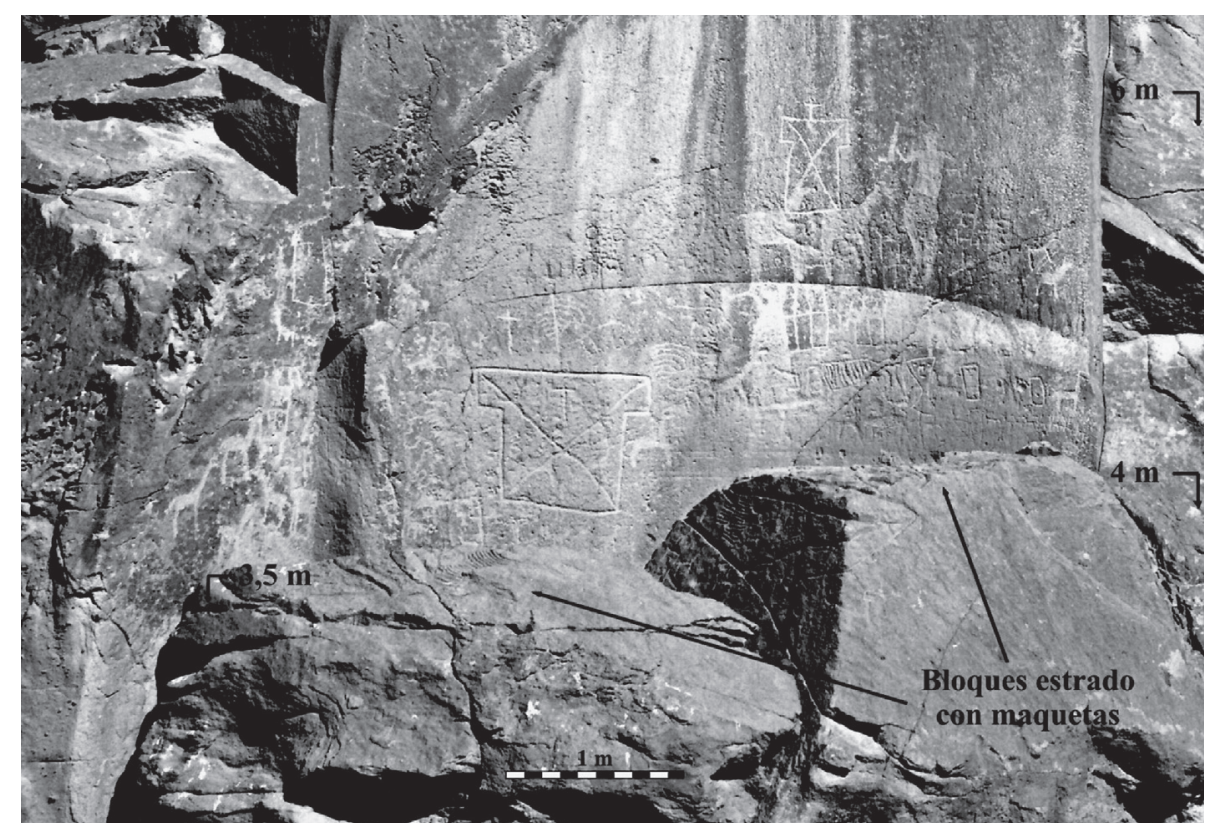

Figura 2: Vista general de las representaciones de la Unidad Topográfica E1.

Figure 2: General view of the depictions of Topographic Unit E1.

A su vez, el acceso al estrado es posible mediante el ascenso por un pequeño espacio entre el frente del farallón y los bloques. Cabe destacar que, tanto las superficies interiores de ese espacio de ascenso como la superficie del estrado, fueron utilizadas para el grabado de diversas representaciones, como camélidos, figuras antropomorfas esquemáticas y dos complejas maquetas que ocupan toda la superficie del estrado (Aschero et al. 2009). La base del registro está conformada por técnicas y métodos convencionales: fotografía digital, calcos en pliegos plásticos, levantamiento de la distribución de las representaciones en el panel a partir de ejes de coordenadas y relevamiento individual de los motivos en ficha de registro (Tabla 1). 
Antes de presentar los datos cuantitativos que refieren al conjunto rupestre analizado, debemos aclarar que los conteos refieren a motivos y no a representaciones, es decir,

"Representación y motivo son entendidos como conceptos que operan en pasos distintos del análisis del contenido de un sitio de arte rupestre. El primero tiene que ver con la segmentación inicial que el analista realiza al observar la superficie del soporte respecto de aquellas que visualiza como unidades discretas (separadas una de otras en el espacio del soporte) y que fueron producidas por un gesto técnico completo; por ejemplo, la figura de un camélido aislado o como parte de una fila, o cada circunferencia o punto de una serie ritmica de repeticiones. El segundo tiene que ver con los vínculos que el analista discrimina entre las representaciones: articulaciones por inclusión, ligaduras, vínculos anecdóticos, etc. Para esta segunda instancia analitica las representaciones se constituyen en motivos o en elementos de un motivo" (Aschero y Martel 2003-2005: 50).

Volviendo al ejemplo del camélido aislado y la caravana, ambos se constituyen en motivos pero, en el primer caso, el camélido aislado es un motivo conformado por una sola representación o elemento, en el segundo, la caravana es un motivo conformado por $n$ representaciones o elementos.

Ahora bien, nuestro registro nos permitió contabilizar 216 representaciones, las que constituyen 97 motivos. Estas cantidades totales, sólo nos sirven para tener una idea de la densidad de representaciones en el panel pero, debido a la ejecución diacrónica de las mismas, la clasificación morfológica del conjunto de representaciones sería irrelevante. Por lo tanto, a partir del registro y análisis de todos aquellos elementos y aspectos representacionales que nos indicaban diacronía de ejecución, construimos una secuencia de producción de las representaciones que nos permitió definir siete momentos distintos, logrando establecer - desde el análisis estilísticola asignación cronológica relativa de cada momento a los diferentes períodos del desarrollo sociocultural local (Figura 3). Para ello se consideraron tres grupos principales de indicadores:

1) Superposiciones, variaciones en la tonalidad de la pátina, representaciones diagnósticas de periodos específicos, registradas también en otros tipos de soporte y con referencias cronológicas (absolutas y/o relativas) confiables.

2) Variaciones estilísticas de las representaciones a nivel intra e intersitio. 
Alvaro Martel, Silvina Rodríguez Curletto y Ezequiel Del Beli

\begin{tabular}{|c|c|c|c|c|c|c|c|c|c|c|c|c|}
\hline \multicolumn{4}{|c|}{ Sitio Confluencia UT El } & \multicolumn{3}{|c|}{ Orient. gral.: E } & \multicolumn{6}{|c|}{ Operadores: S. Rodríguez Curletto, E. Del Bel, A. Martel - 26 al 28/02/07 } \\
\hline \multicolumn{2}{|c|}{\begin{tabular}{|l|l|l|l} 
U.T &
\end{tabular}} & \multirow{2}{*}{\begin{tabular}{|l|}
$\begin{array}{l}\text { Mo- } \\
\text { tivo }\end{array}$ \\
$\mathrm{N}^{\circ}$ \\
\end{tabular}} & \multirow{2}{*}{\begin{tabular}{|l|} 
Serie \\
cro- \\
noló- \\
gica
\end{tabular}} & \multicolumn{2}{|c|}{ Motivo } & \multirow{2}{*}{\begin{tabular}{|l|} 
Can- \\
tidad \\
Ele- \\
men- \\
tos
\end{tabular}} & \multirow{2}{*}{\begin{tabular}{|l|} 
Designación morfológica \\
del Motivo
\end{tabular}} & \multirow{2}{*}{\begin{tabular}{|l|} 
Ancho $\mathrm{mm}$ \\
sco/trazo
\end{tabular}} & \multirow{2}{*}{\begin{tabular}{|l|} 
Grabado \\
Mod.tec. \\
\end{tabular}} & \multirow{2}{*}{\begin{tabular}{|l|} 
Pintura \\
$\begin{array}{l}\text { Mod. } \\
\text { tec. }\end{array}$ \\
\end{tabular}} & \multirow{2}{*}{\begin{tabular}{|l|} 
Patina o \\
tonalidad
\end{tabular}} & Superpo- \\
\hline $\mathbf{N}^{\circ}$ & Orient. & & & \begin{tabular}{|l|} 
Largo \\
$(\mathrm{cm})$ \\
$\uparrow$ \\
$\uparrow$
\end{tabular} & $\begin{array}{l}\text { Ancho } \\
\text { (cm) } \\
\leftrightarrow\end{array}$ & & & & & & & \begin{tabular}{|l} 
(sobre/ \\
bajo) $\mathbf{N}^{\circ}$
\end{tabular} \\
\hline 1.1 & NE & 1 & $\mathrm{C}$ & 39 & 31 & 1 & Cam. der. 2p. cola or. & $8 \mathrm{a} 20 / 35 \mathrm{a} 70$ & PSPP1 & $\ldots$ & Débil & \\
\hline 1.1 & $\mathrm{NE}$ & 2 & $\mathrm{C}$ & 36 & 25 & 1 & Cam. der. 2p. cola or. & $7 \mathrm{a} 22 / 40 \mathrm{a} 72$ & PSPP1 & $\ldots$ & Débil & 25 \\
\hline 1.1 & $\mathrm{NE}$ & 3 & $\mathrm{C}$ & 31 & 21 & 1 & Cam. der. 2p. cola or. & $9 \mathrm{a} 13 / 25 \mathrm{a} 70$ & PSPP1 & $\ldots$ & Débil & $\ldots$ \\
\hline 1.1 & $\mathrm{NE}$ & 4 & C & 30 & 28 & 1 & Cam. izq. 2p. cola or. & $7 \mathrm{a} 25 / 50$ & PSPP1 & $\ldots$ & Débil & $\ldots$ \\
\hline 1.1 & $\mathrm{NE}$ & 5 & B2 & 53 & 34 & 9 & Antrop. front. toc. 2 br. $2 \mathrm{p}$. & 5 a 40 & PS & $\ldots$ & Débil & 25 \\
\hline 1.1 & $\mathrm{NE}$ & 6 & C & 22 & 19 & 1 & $\begin{array}{l}\text { Cam izq. 2p. cola or. vient. } \\
\text { acu. }\end{array}$ & $10 \mathrm{a} 43 / 40 \mathrm{a} 67$ & PSPP1 & $\ldots$ & Débil & $\mathrm{Si}$ \\
\hline 1.1 & $\mathrm{NE}$ & 7 & $\mathrm{D}$ & 38 & 25 & 2 & $\begin{array}{l}\text { Posible escutiforme c/cabeza } \\
\text { en T }\end{array}$ & 8 a 10 & PS & $\cdots$ & Débil & $\ldots$ \\
\hline 1.1 & $\mathrm{NE}$ & 8 & C & 6 & 10 & 6 & Huella felino & 15 a 30 & Puntiforme & $\ldots$ & Débil & $\ldots$ \\
\hline 1.1 & $\mathrm{NE}$ & 9 & $\mathrm{C}$ & 28 & 28 & 1 & Cam izq. cabeza der s/p oreja & 10a20/40a125 & PSPP1 & $\ldots$ & Moderada & $10 / 9$ \\
\hline 1.1 & $\mathrm{NE}$ & 10 & $\mathrm{D}$ & 25 & 20 & 1 & $\begin{array}{l}\text { Antrop. T portando posible } \\
\text { objeto }\end{array}$ & 5 a 25 & PS & $\ldots$ & Débil & $10 / 9$ \\
\hline 1.1 & $\mathrm{NE}$ & 11 & E & 8 & 8 & 1 & Cam. der. 2p. cola or. & 8 a 20 & PS & $\ldots$ & Débil & $\ldots$ \\
\hline 1.3 & $\mathrm{E}$ & 12 & E & 8 & 7 & 1 & Cam. der. 2p. cola or. & 5 a 15 & PSA & $\ldots$ & Débil & $\ldots$ \\
\hline 1.3 & $\mathrm{E}$ & 13 & E & 12 & 16 & 1 & Cam. der. 2p. cola & 8 a 20 & PS & $\ldots$ & Débil & $\ldots$ \\
\hline 1.3 & E & 14 & E & 24 & 12 & 1 & Cam. izq. vert. 2 p. cola or. & $20 \times 25$ & PS & $\ldots$ & Débil & $\ldots$ \\
\hline 1.3 & E & 15 & C & 53 & 29 & 1 & Maqueta combinada & 8 a 20 & PS & $\ldots$ & Débil & $16 / 15$ \\
\hline 1.3 & E & 16 & C & 57 & 12 & 25 & Huellas felino (5) & 10 a 27 & Puntiforme & $\ldots$ & Débil & $16 / 15$ \\
\hline 1.3 & E & 17 & C & 34 & 13 & 1 & Indeterminado & 12 a 24 & PS & $\ldots$ & Débil & $\ldots$ \\
\hline 1.3 & $\mathrm{E}$ & 18 & C & 16 & 13 & 1 & Cam. izq. 2p. cola 2or. & $5 \mathrm{a} 15 / 30$ & PSPP1 & $\ldots$ & Dé-Mo & $\ldots$ \\
\hline 1.3 & E & 19 & B2 & 28 & 14 & 1 & Cartucho doble & 3 & Inciso & $\ldots$ & Débil & $\ldots$ \\
\hline 1.3 & E & 20 & E & 13 & 17 & 1 & Cam. der. 2p. or. c/carga & 10 a 15 & PS & $\ldots$ & Débil & $\ldots$ \\
\hline 1.3 & E & 21 & B2 & 26 & 18 & 1 & $\begin{array}{l}\text { Antrop. front. esq. lin. br. } \\
\text { levant. }\end{array}$ & 6 a 15 & PSA & $\ldots$ & Débil & $\ldots$ \\
\hline 1.3 & E & 22 & C & 26 & 8 & 15 & Huellas felino (3) & $10 \times 25$ & Puntiforme & $\ldots$ & Débil & $\ldots$ \\
\hline 1.3 & E & 23 & C & 10 & 11 & 1 & Indeterminado & 10 a 25 & PS & $\ldots$ & Débil & $\ldots$ \\
\hline 1.3 & E & 24 & $\mathrm{Bl}$ & 30 & 32 & 1 & $\begin{array}{l}\text { Cam. izq. contorno lin. } \\
\text { abierto }\end{array}$ & 4 a 7 & PSIn. & $\ldots$ & Fuerte & $25-26 / 24$ \\
\hline 1.3 & E & 25 & $F$ & 27 & 12 & 1 & Cruz histórica & 10 a 22 & PSA & $\ldots$ & Débil & $25 / 24$ \\
\hline 1.3 & E & 26 & C & 36 & 39 & 2 & Rheido - Suri & 7 a 18 & PS & $\ldots$ & Dé-Mo & $26 / 24-30$ \\
\hline 1.3 & $\mathrm{E}$ & 27 & A & 26 & 18 & 1 & Espiral & 9 a 18 & $\ldots$ & Lineal & Rojo desv. & \\
\hline 1.3 & E & 28 & $\mathrm{~A}$ & 42 & 18 & 1 & Figura geométrica en $\mathrm{T}$ & 18 a 21 & $\ldots$ & Lineal & Rojo desv. & $29 / 28$ \\
\hline 1.3 & $\mathrm{E}$ & 29 & $\mathrm{Bl}$ & 17 & 8 & 1 & Bidente & 18 a 25 & PS & $\ldots$ & Débil & $29 / 28$ \\
\hline 1.3 & E & 30 & $\mathrm{Bl}$ & 77 & 27 & 16 & Felino & $24 / 15 / 36$ & \begin{tabular}{|l|} 
Punt. \\
PSPP1 \\
\end{tabular} & $\ldots$ & Moderada & $26 / 30$ \\
\hline 1.3 & $\mathrm{E}$ & 31 & $\mathrm{Bl}$ & 21 & 9 & 1 & Huella humana & $8 \mathrm{a} 22 / 40 \mathrm{a} 65$ & PSPP1 & $\begin{array}{ll}\ldots \\
\end{array}$ & Moderada & \\
\hline 1.3 & E & 32 & $\mathrm{~A}$ & 26 & 24 & 4 & Geométrico cuadrangular & 16 a 20 & & Lineal & Rojo desv. & $33 / 32$ \\
\hline 1.3 & E & 33 & $\mathrm{D}$ & 82 & 99 & 2 & Antropomorfo T & $14 \mathrm{a} 20 / 21 \mathrm{a} 26$ & PSAPS & ... & Débil & $\begin{array}{l}33 / 32-35- \\
36 \text { y } 34 / 33\end{array}$ \\
\hline 1.3 & E & 34 & $F$ & 18 & 7 & 1 & Cruz histórica & 8 a 12 & PSA & $\ldots$ & \begin{tabular}{|l|} 
Relleno \\
arc.
\end{tabular} & $34 / 33$ \\
\hline 1.3 & E & 35 & C & 25 & 29 & 1 & Cam. der. 2p. cola & $8 / 30 a 75$ & PSPP1 & $\ldots$ & Débil & $33 / 35$ \\
\hline 1.3 & E & 36 & C & 14 & 13 & 1 & Cam izq. 2 p cola or. & $5 a 9 / 20 a 35$ & PSPP1 & $\ldots$ & Dé-Mo & $33 / 36$ \\
\hline 1.3 & E & 37 & C & 15 & 13 & 1 & $\begin{array}{l}\text { Geométrico T contorno lin. } \\
\text { abierto }\end{array}$ & 8 a 10 & PSA & $\ldots$ & Débil & $\ldots$ \\
\hline 1.3 & E & 38 & C & 16 & 13 & 1 & Cam. der. 2 p cola or. & $9 \mathrm{a} 12 / 30 \mathrm{a} 38$ & PSPP1 & $\ldots$ & Dé-Mo & $\ldots$ \\
\hline 1.3 & E & 39 & C & 11 & 12 & 1 & Indeterminado & 24 a 29 & PP1A & $\ldots$ & Débil & $\ldots$ \\
\hline 1.3 & $\mathrm{E}$ & 40 & C & 6 & 23 & 1 & Indeterminado & 25 a 56 & PP1 & $\ldots$ & Débil & $\ldots$ \\
\hline 1.3 & E & 41 & B2 & 11 & 7 & 2 & Cartucho & $2 \mathrm{a} 4$ & Inciso & $\ldots$ & Débil & $\ldots$ \\
\hline 1.3 & $E$ & 42 & C & 13 & 11 & 1 & $\begin{array}{l}\text { Geométrico surco lineal } \\
\text { oblicuo }\end{array}$ & 15 & PS & $\ldots$ & Débil & $\ldots$ \\
\hline 1.3 & E & 43 & B2 & 8 & 8 & 2 & Huella camélido & 18 & PS & $\ldots$ & Moderada & $\ldots$ \\
\hline 1.3 & E & 44 & B2 & 4,5 & 13 & 1 & Cartucho & 4 & Inciso & $\ldots$ & Débil & $\ldots$ \\
\hline 1.3 & E & 45 & C & 10 & 9 & 1 & Geométrico lineal en $\mathrm{H}$ & $7 \mathrm{a} 1 \mathrm{O} / 25$ & PSPP1 & $\ldots$ & Débil & $\ldots$ \\
\hline 1.3 & $E$ & 46 & C & 22 & 21 & 1 & Cam. der. 2p. cola or. & $6 / 20 \mathrm{a} 64$ & PSPP1 & $\ldots$ & $\begin{array}{l}\text { Relleno } \\
\text { arc. }\end{array}$ & $\ldots$ \\
\hline 1.3 & $\mathrm{E}$ & 47 & C & 16 & 12 & 1 & $\begin{array}{l}\text { Cam. der. 2p_cola or. hacia } \\
\text { atrás }\end{array}$ & $8 \mathrm{al} 2 / 44$ & PSPP1 & $\ldots$ & $\begin{array}{l}\text { Relleno } \\
\text { arc. }\end{array}$ & $\cdots$ \\
\hline 1.3 & $E$ & 48 & C & 34 & 31 & 1 & Cam. der. 2p. cola or & $13 \mathrm{a} 20 / 25 \mathrm{a} 8 \mathrm{O}$ & PSPP1 & $\ldots$ & \begin{tabular}{|l|} 
Relleno \\
arc.
\end{tabular} & $\cdots$ \\
\hline 1.3 & $\mathrm{E}$ & 49 & C & 37 & 41 & 1 & Rheido - Suri & 8 a 15 & PS & $\ldots$ & $\begin{array}{l}\text { Dé+Rell } \\
\text { arc. }\end{array}$ & $\ldots$ \\
\hline 1.3 & $\mathrm{E}$ & 50 & $\mathrm{C}$ & 46 & 35 & 1 & Cam. der. 2p. cola or. & $10 \mathrm{a} 15 / 18 \mathrm{a} 60$ & PSPP1 & $\cdots$ & $\begin{array}{l}\text { D-M-Rell, } \\
\text { arc. }\end{array}$ & $\cdots$ \\
\hline 1.3 & E & 51 & B2 & 22 & 15 & 1 & Cartucho doble & 3 a 4 & Inciso & $\ldots$ & Fuerte & $\ldots$ \\
\hline 1.3 & E & 52 & B2 & 16 & 6,5 & 2 & Cartucho & 2 a 4 & Inciso & $\ldots$ & Fuerte & $\ldots$ \\
\hline 1.3 & $\mathrm{E}$ & 53 & NA & 42 & 28 & NR & Indeterminado & $3 / 15 / 40$ & IncPSPPl & $\ldots$ & $\begin{array}{l}\text { Relleno } \\
\text { arc. }\end{array}$ & NR \\
\hline 1.3 & E & 54 & B2 & 15 & 11 & 1 & Geométrico trapezoidal & 10 a 15 & PS & $\ldots$ & \begin{tabular}{|l|} 
Relleno \\
arc.
\end{tabular} & $\ldots$ \\
\hline 1.3 & E & 55 & B2 & 10 & 7 & 1 & Cartucho c/base abierta & 3 a 5 & PSF & $\ldots$ & Fuerte & $\ldots$ \\
\hline 1.3 & E & 56 & B2 & 6 & 5 & 2 & Huella camélido & 20 & PS & $\ldots$ & Fuerte & $\ldots$ \\
\hline 1.3 & E & 57 & $\mathrm{C}$ & 25 & 12 & 1 & Cam. der. 2p. cola or. & $9 \mathrm{a} 22 / 24 \mathrm{a} 28$ & PSPP1 & $\ldots$ & Mo-Fu & $\ldots$ \\
\hline
\end{tabular}


Arte Rupestre y Espacios de Memoria: Las Representaciones del Sitio Confluencia

\begin{tabular}{|c|c|c|c|c|c|c|c|c|c|c|c|c|}
\hline \multicolumn{4}{|c|}{ Sitio Confluencia UT El } & \multicolumn{3}{|c|}{ Orient. gral.: E } & \multicolumn{6}{|c|}{ Operadores: S. Rodríguez Curletto, E. Del Bel, A. Martel - 26 al 28/02/07 } \\
\hline \multicolumn{2}{|c|}{\begin{tabular}{|l|l|l|l} 
U.T &
\end{tabular}} & \multirow{2}{*}{\begin{tabular}{|l|}
$\begin{array}{l}\text { Mo- } \\
\text { tivo }\end{array}$ \\
$\mathrm{N}^{\circ}$
\end{tabular}} & \multirow{2}{*}{\begin{tabular}{|l|}
$\begin{array}{l}\text { Serie } \\
\text { cro- } \\
\text { noló- } \\
\text { gica }\end{array}$ \\
\end{tabular}} & \multicolumn{2}{|c|}{ Motivo } & \multirow{2}{*}{\begin{tabular}{|l|} 
Can- \\
tidad \\
Ele- \\
men- \\
tos
\end{tabular}} & \multirow{2}{*}{\begin{tabular}{|l|} 
Designación morfológica \\
del Motivo
\end{tabular}} & \multirow{2}{*}{\begin{tabular}{|l|} 
Ancho mm \\
sco/trazo
\end{tabular}} & \multirow{2}{*}{\begin{tabular}{|l|} 
Grabado \\
Mod.tec. \\
\end{tabular}} & \multirow{2}{*}{\begin{tabular}{|l|} 
Pintura \\
$\begin{array}{l}\text { Mod. } \\
\text { tec. }\end{array}$ \\
\end{tabular}} & \multirow{2}{*}{\begin{tabular}{|l|} 
Patina o \\
tonalidad
\end{tabular}} & \multirow{2}{*}{\begin{tabular}{|l|}
$\begin{array}{l}\text { Superpo- } \\
\text { siciones }\end{array}$ \\
(sobre/ \\
bajo) $\mathrm{N}^{\circ}$
\end{tabular}} \\
\hline $\mathbf{N}^{\circ}$ & Orient. & & & \begin{tabular}{|l|} 
Largo \\
$(\mathbf{c m})$ \\
$\uparrow$ \\
$\uparrow$
\end{tabular} & \begin{tabular}{|l} 
Ancho \\
$(\mathrm{cm})$
\end{tabular} & & & & & & & \\
\hline 1.3 & E & 58 & B2 & 18 & 40 & 1 & $\begin{array}{l}\text { Geom.trapez.irreg. c/scos. } \\
\text { vert.paral. }\end{array}$ & 5 a 18 & PS & $\ldots$ & $\begin{array}{l}\text { Mo+Rell. } \\
\text { arc. }\end{array}$ & $\ldots$ \\
\hline 1.3 & $E$ & 59 & B2 & 40 & 26,5 & 1 & Rectángulo c/ret. int & 5 a 17 & PSA & $\ldots$ & \begin{tabular}{|l|} 
Relleno \\
arc.
\end{tabular} & $\ldots$ \\
\hline 1.3 & E & 60 & B2 & 18 & 17 & 1 & Cuadrado c/div. vert. int. & 5 a 16 & PS & $\ldots$ & Moderada & $\ldots$ \\
\hline 1.3 & E & 61 & B1 & 22 & 23 & 1 & Figura zoomorfa indet. & $8 / 70$ & Punt.PPl & $\ldots$ & Fuerte & $62 / 61$ \\
\hline 1.3 & $\mathrm{E}$ & 62 & B2 & 22 & 21 & 6 & Conjunto $s c o s$, inc. paralelos & 2 a 4 & Inciso & $\ldots$ & Fuerte & $62 / 61$ \\
\hline 1.3 & E & 63 & B2 & 20.5 & 25 & 1 & Cartucho triple & 2 a 4 & Inciso & $\ldots$ & Fuerte & $66 / 63$ \\
\hline 1.3 & E & 64 & B2 & 11 & 10 & 1 & Cartucho & 4 a 8 & PSF & $\ldots$ & Fuerte & $\ldots$ \\
\hline 1.3 & E & 65 & B2 & 21 & 9 & 1 & Cartucho c/ret. oblicuo & $1,5 \mathrm{a} 4$ & Inciso & $\ldots$ & Fuerte & $\ldots$ \\
\hline 1.3 & $\mathrm{E}$ & 66 & B2 & 33 & 19 & 7 & $\begin{array}{l}\text { Masc, de contorno geom. } \\
\text { indet. }\end{array}$ & 3 a 10 & PSA & $\ldots$ & \begin{tabular}{|l} 
Relleno \\
arc.
\end{tabular} & $66 / 63$ \\
\hline 1.3 & E & 67 & B2 & 23 & 16 & 1 & $\begin{array}{l}\text { Geométrico en forma de } \\
\text { botella }\end{array}$ & 10 a 20 & PS & $\cdots$ & Fuerte & $\cdots$ \\
\hline 1.3 & $\mathrm{E}$ & 68 & B2 & 15 & 12 & 1 & Geométrico en T & 6 a9 & PS & $\ldots$ & Moderada & $\ldots$ \\
\hline 1.3 & $\mathrm{E}$ & 69 & B2 & 18 & 11 & 5 & Mascariforme rectangular & 5 a 10 & PS & $\ldots$ & Débil & $\ldots$ \\
\hline 1.3 & E & 70 & C & 14 & 11 & 1 & Cam. der. 2p. cola or. & $5 a 7 / 25 a 35$ & PSPP1 & $\ldots$ & Débil & $\ldots$ \\
\hline 1.3 & E & 71 & B2 & 36 & 14 & 5 & Antrop. s/brazos c/rostro & $2 / 10 / 40$ & IncPSPPl & $\ldots$ & Débil & $\ldots$ \\
\hline 1.3 & E & 72 & B2 & 8 & 9 & 5 & Huella felino & 20 y 50 & Puntiforme & $\ldots$ & Débil & $\ldots$ \\
\hline 1.3 & E & 73 & B2 & 10 & 11 & 6 & Huella felino & 15 y 55 & Puntiforme & $\ldots$ & Débil & $\ldots$ \\
\hline 1.3 & $\mathrm{E}$ & 74 & B2 & 17 & 10 & 2 & Cartucho c/puntiformes int. & 19/6al4 & Punt.PS & $\ldots$ & Débil & $\ldots$ \\
\hline 1.3 & E & 75 & C & 25 & 21 & 1 & Cam. der. 2 p. cola or. & $9 a 10 /-25 a 42$ & PSPP1 & $\ldots$ & $\begin{array}{l}\text { Relleno } \\
\text { arc. }\end{array}$ & $\ldots$ \\
\hline 1.3 & $E$ & 76 & E & 13 & 60 & 8 & Caravana & $\ldots$ & PS & $\ldots$ & $\ldots$ & $\ldots$ \\
\hline 1.3 & E & $76 a$ & E & 9 & 11,5 & 1 & Cam. izq 2 p cola or. & 7 a9 & PS & $\ldots$ & Fuerte & $\ldots$ \\
\hline 1.3 & E & $76 \mathrm{~b}$ & E & 8.5 & 7,5 & 1 & Cam izq 2p cola or. & 7 a9 & PS & $\ldots$ & Fuerte & $\ldots$ \\
\hline 1.3 & E & $76 c$ & E & 9.3 & 8,6 & 1 & Cam izq 2p cola or. & 7 a9 & PS & $\ldots$ & Fuerte & $\ldots$ \\
\hline 1.3 & E & $76 \mathrm{~d}$ & E & 9 & 9,3 & 1 & Cam. izq. 2p. cola or. & 7 a9 & PS & $\ldots$ & Fuerte & $\ldots$ \\
\hline 1.3 & $\mathrm{E}$ & $76 \mathrm{e}$ & E & 9 & 8,8 & 1 & Cam. izq. 2p. cola or. & 7 a9 & PS & $\ldots$ & Débil & $\ldots$ \\
\hline 1.3 & $\mathrm{E}$ & $76 f$ & E & 9 & 9,4 & 1 & Cam izq 2p cola or. & 7 a9 & PS & $\ldots$ & Débil & $\ldots$ \\
\hline 1.3 & $E$ & $76 \mathrm{~g}$ & $E$ & 9 & 7,5 & 1 & Cam. izq 2 p cola or. & 7 a9 & PS & $\ldots$ & \begin{tabular}{|l} 
Dé+Rell \\
arc.
\end{tabular} & $\ldots$ \\
\hline 1.3 & E & $76 \mathrm{~h}$ & E & 8 & 8 & 1 & Cam izq $2 p$ cola or. & 7 a 9 & PS & $\ldots$ & \begin{tabular}{|l} 
Dé+Rell \\
arc.
\end{tabular} & $\cdots$ \\
\hline 1.3 & $\mathrm{E}$ & 77 & C & 57 & 41 & 1 & Cam. der. 2p. cola or & $1 / 40$ a 190 & PSPP1 & $\ldots$ & $\begin{array}{l}\text { Relleno } \\
\text { arc. }\end{array}$ & $82 / 77$ \\
\hline 1.3 & $E$ & 78 & C & 59 & 47 & 1 & Cam. der. 2p. cola or. & 30 a 165 & PP1 & $\ldots$ & \begin{tabular}{|l|} 
Relleno \\
arc.
\end{tabular} & $82 / 78$ \\
\hline 1.3 & $E$ & 79 & C & 94 & 49 & 1 & $\begin{array}{l}\text { Antrop. c/toc portando } \\
\text { objeto }\end{array}$ & $\begin{array}{l}2 / 20-40-55- \\
200\end{array}$ & IncPPl & $\ldots$ & $\begin{array}{l}\text { Mo-Rell } \\
\text { arc. }\end{array}$ & $\ldots$ \\
\hline 1.3 & E & 80 & C & 24 & 19 & 1 & Cam izq. 2p cola or. & 11 a 15 & PSPP1 & $\ldots$ & \begin{tabular}{|l} 
Relleno \\
arc.
\end{tabular} & $\ldots$ \\
\hline 1.3 & $E$ & 81 & B2 & 14 & 13 & 1 & $\begin{array}{l}\text { Cuadrado c/divisiones } \\
\text { vert. int. }\end{array}$ & 3all & PS & $\ldots$ & \begin{tabular}{|l} 
Relleno \\
arc.
\end{tabular} & $\ldots$ \\
\hline 1.3 & $\mathrm{E}$ & 82 & $\mathrm{D}$ & 54 & 40 & 1 & Antropomorfo T & 10 a 16 & PS & $\ldots$ & \begin{tabular}{|l|} 
Relleno \\
arc. \\
\end{tabular} & $82 / 77-78$ \\
\hline 1.3 & $E$ & 83 & B2 & 33 & 54 & 1 & Zoomorfo & $9 \mathrm{a} 12 / 43 \mathrm{a} 70$ & PSPP1 & $\ldots$ & $\begin{array}{l}\text { Mo+Rell } \\
\text { arc. }\end{array}$ & $\cdots$ \\
\hline 1.3 & E & 84 & E & 16 & 14 & 1 & Cam. der. 2p. or. & 10 a 20 & PS & $\ldots$ & Débil & $\mathrm{Si}$ \\
\hline 1.3 & E & 85 & E & 11 & 16 & 1 & Cam izq 2p cola or. & 4 a 16 & PS & $\ldots$ & Débil & $\ldots$ \\
\hline 1.3 & E & 86 & C & 19 & 15 & 1 & Geométrico lineal cruciforme & 10 a 35 & PS & $\ldots$ & Débil & $\ldots$ \\
\hline 1.3 & E & 87 & B2 & 7 & 7 & 1 & Antropomorfo s/cabeza & 5 a 23 & PS & $\ldots$ & Débil & $\ldots$ \\
\hline 1.3 & E & 88 & B2 & 50 & 16 & 1 & Antrop. en bloq. c/tocado & 20 a 130 & PP1 & $\ldots$ & Débil & \\
\hline 1.3 & E & 89 & E & 19 & 19 & 1 & Cam. der. 2p. cola or. & 12 a 35 & PS & $\ldots$ & \begin{tabular}{|l|}
$\begin{array}{l}\text { Relleno } \\
\text { arc. }\end{array}$ \\
\end{tabular} & $\mathrm{Si}$ \\
\hline 1.3 & $E$ & 90 & C & 22 & 21 & 1 & Cam. der. 2p. cola or. & $5 \mathrm{a} 8 / 22 \mathrm{a} 70$ & PSPP1 & $\cdots$ & \begin{tabular}{|l|} 
Relleno \\
arc.
\end{tabular} & $\mathrm{Si}$ \\
\hline 1.3 & $E$ & 91 & E & 11 & 16 & 1 & Cam izq 2p cola or. & 10 a 25 & PS & $\ldots$ & Débil & $\ldots$ \\
\hline 1.2 & SE & 92 & E & 16 & 15 & 1 & Cam. der. 2p. cola or. & 10a 15 & PS & $\ldots$ & Débil & $\ldots$ \\
\hline 1.2 & SE & 93 & E & 13 & 15 & 1 & Cam. der. 2p. cola or. & 10 a 15 & PS & $\ldots$ & Débil & $\ldots$ \\
\hline 1.2 & SE & 94 & E & 13 & 14 & 1 & Cam der. 2p. cola or. & 10a 15 & PS & $\ldots$ & Débil & $\ldots$ \\
\hline 1.2 & SE & 95 & C & 29 & 16 & 1 & $\begin{array}{l}\text { Geom. subrectang. cont. lin. } \\
\text { cerrado }\end{array}$ & 10 a 12 & PS & $\ldots$ & Débil & $\ldots$ \\
\hline 1.2 & SE & 96 & E & 11 & 10 & 1 & Cam. der. 2p. cola or. & 12 a 15 & PS & $\ldots$ & Débil & $\ldots$ \\
\hline 1.2 & SE & 97 & $\mathrm{E}$ & 12 & 11 & 1 & Cam. der. 2p. cola or. & 10 a 20 & PS & $\ldots$ & Débil & \\
\hline
\end{tabular}

Tabla 1: Registro de las representaciones rupestres del sitio Confluencia Unidad Topográfica E1.

Table 1: Record of rupestrian figures in Confluencia site, Topograbic Unit E1. 
3) Características del uso del espacio plástico, considerando dimensiones relativas de los motivos, posición en el panel y recursos técnicos de ejecución.

Cf, UT E1. Total motivos por momento

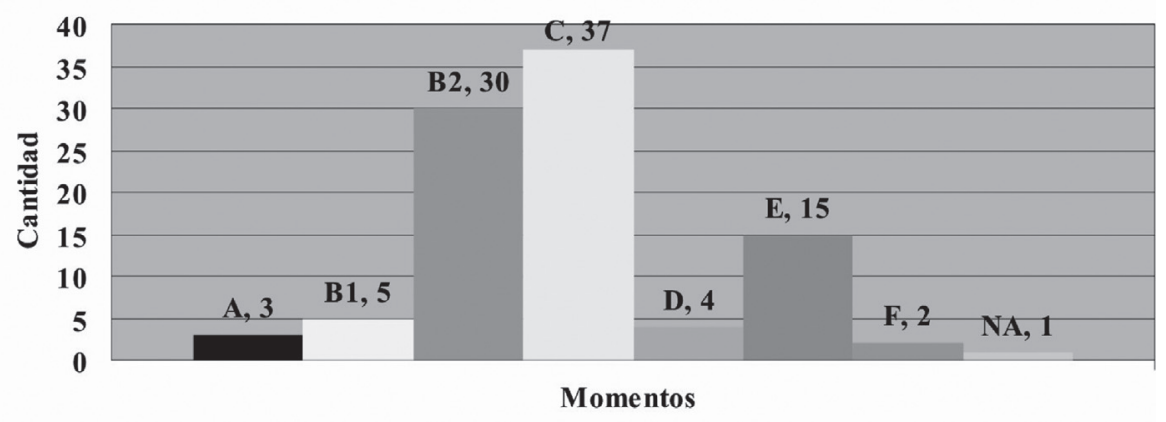

A Arcaico

B2 Formativo

D Tardío Final

- F Hispano Indíge na
B1 Arcaico Tardío/Formativo Temprano

C Tardío

E Tardío/Inka

NA No as ignadas

Figura 3: Cantidad de motivos por momento de ejecución en la UT E1.

Figure 3: Number of motifs by period of production in the UT E1.

La manera que hemos elegido para graficar esta información se realizó mediante la reconstrucción de la distribución de las representaciones en el panel a partir de sus respectivas coordenadas de relevamiento y su área de representación (Figura 4). Destacamos que las superposiciones que se observan entre los recuadros que limitan el área de representación de cada motivo, no implica la superposición de tales motivos ya que el recuadro sólo señala las medidas máximas, de largo (vertical) y ancho (horizontal), en cual se encuadra el motivo.

\section{Momento A}

Comprende restos de tres motivos geométricos, pintados en rojo, muy desvaídos (Figura 5). Sobre uno de ellos (motivo no 28), se puede apreciar el grabado de un motivo bidente (motivo no 29) correspondiente a la modalidad estilística Río Punilla -2000 a 500 a.C.- (Aschero 1999). Este hecho nos lleva pensar a una ejecución más temprana de las pinturas, asignable a la modalidad estilística Quebrada Seca -3500 a 2000 a.C.- del período Arcaico Tardío y asociadas a un contexto de producción de grupos cazadores recolectores (Aschero 2006). 


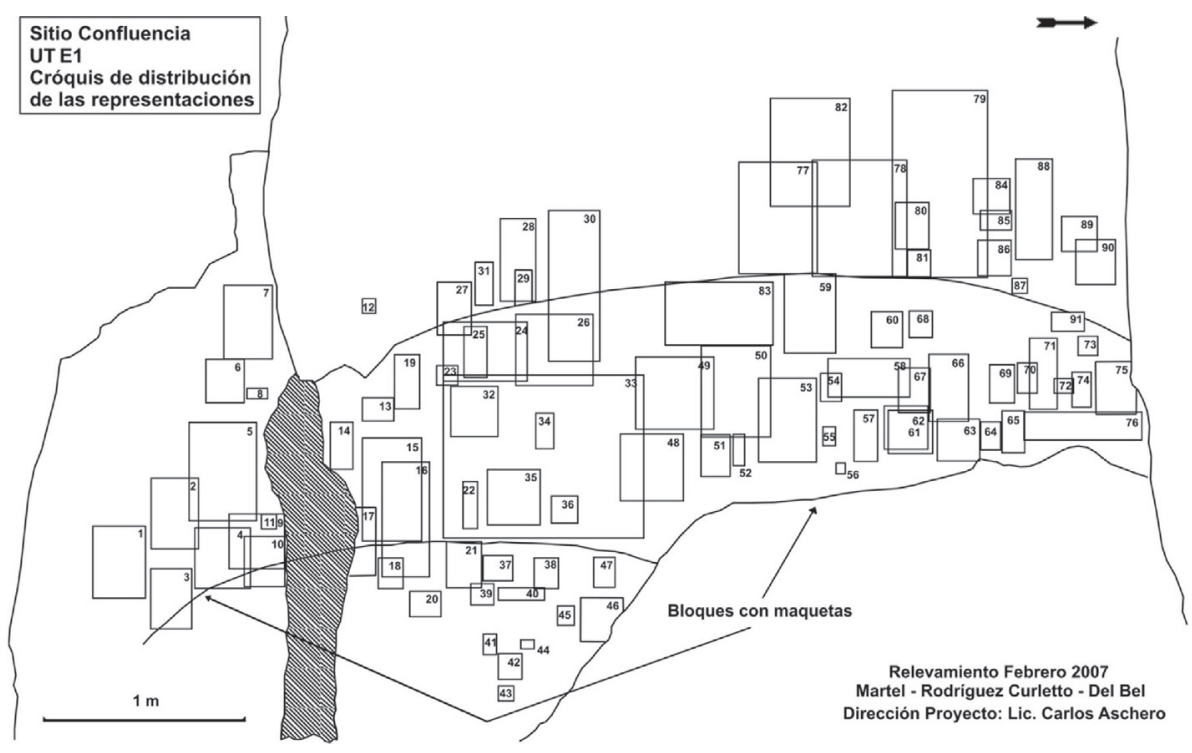

Figura 4: Distribución de los motivos considerando su área de representación.

Figure 4: Distribution of the motifs considering their area of representation.

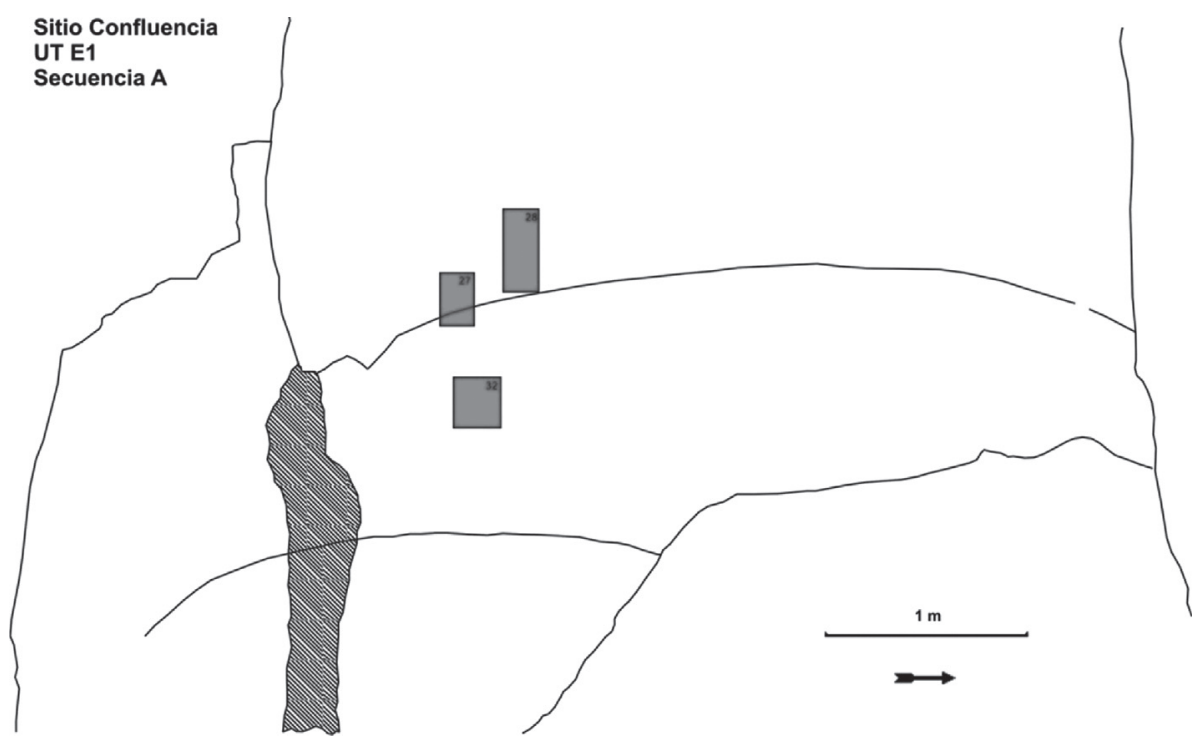

Figura 5: Distribución de los motivos del momento A, Arcaico Tardío.

Figure 5: Distribution of Late Archaic motifs, moment A. 


\section{Momento B1}

Las representaciones de este momento comprenden cinco motivos grabados (Figura 6). Tres de estos (mots. no 29, 30 y 31), fueron adscriptos por Aschero (2006: 131, fig.20) a la modalidad estilística Río Punilla. Esta modalidad, siguiendo al autor citado, se vincula al período de transición de grupos con economías extractivas hacia formas productivas, en un lapso que abarcaría los últimos siglos del Arcaico Tardío y los primeros del Formativo Temprano. Si bien esta modalidad introducirá nuevos temas y patrones de diseño al repertorio iconográfico local, una de sus principales características consiste en la continuidad que establece con modalidades anteriores, tanto en la reproducción de algunas de figuras antiguas como en la elección de los emplazamientos para las mismas.

\section{Momento B2}

Este momento presenta sustanciales diferencias con los anteriores. En primer lugar, aumentan considerablemente la cantidad de representaciones (71 representaciones que conforman 30 motivos), y en segundo lugar, se aprecian nuevas pautas en la selección de los sectores del soporte donde se realizaron las mismas. Las representaciones de este momento, todas ejecutadas mediante grabado, se agrupan principalmente hacia la parte media inferior del lado derecho del panel, relativamente próximas a los motivos precedentes (Figura 7).

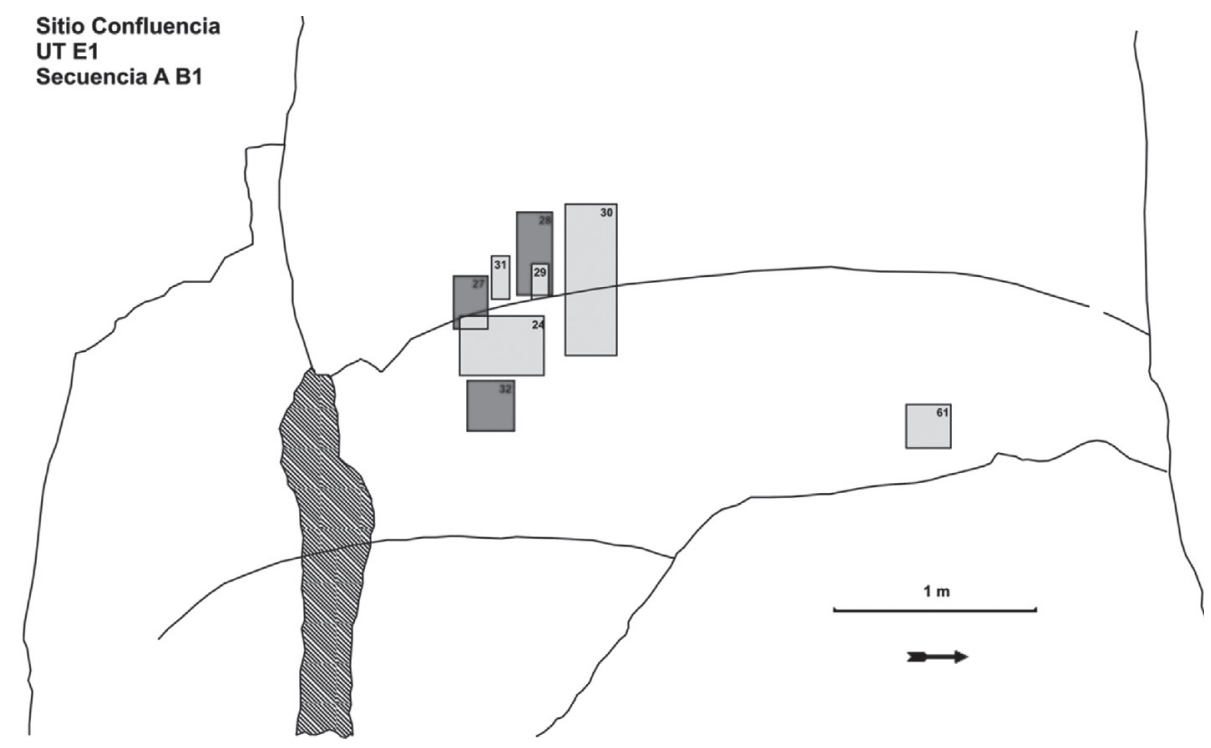

Figura 6: Distribución de los motivos del momento B1, Arcaico Tardio/Formativo Temprano.

Figure 6: Distribution of Late Archaic/Early Formative motifs, moment B1. 


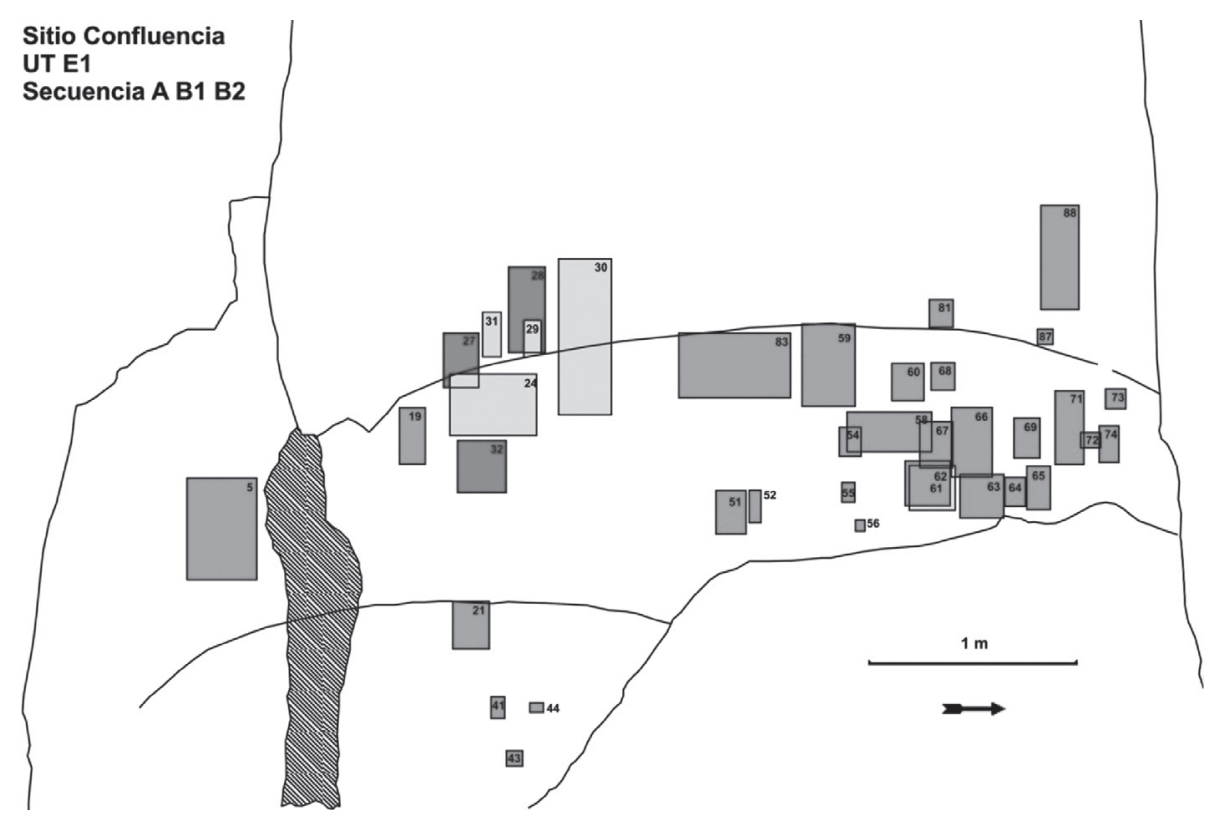

Figura 7: Distribución de los motivos del momento B2, periodo Formativo.

Figure 7: Distribution of Formative period motifs, moment B2.

Desde un análisis morfoestilístico, las representaciones del momento B2, presentan las características generales del arte rupestre Formativo local, haciendo posible la asignación a sus dos principales modalidades estilísticas: Peñas Coloradas -500 a.C. a 300 d.C.- y Peñas Chicas -300 a 500 d.C-. En el conjunto nos interesa destacar la presencia de dos tipos de motivos particulares, nos referimos a aquellos que aluden a lo humano (antropomorfos y mascariformes/rostros) y a los rectángulos con diseños geométricos internos o cartuchos (Figura 8). Tal asociación de motivos conforma el tema figura humana-cartucho, el cual, muchas veces, próximo o compartiendo soporte con representaciones de maquetas, ha sido registrado en ANS en diversos sitios de cronología similar y vinculado a emplazamientos con buen potencial agrícola, sectores de enterramiento y caminos (Aschero et al. 2006 y 2009). 


\section{Total de motivos por tipo, Momento B2}

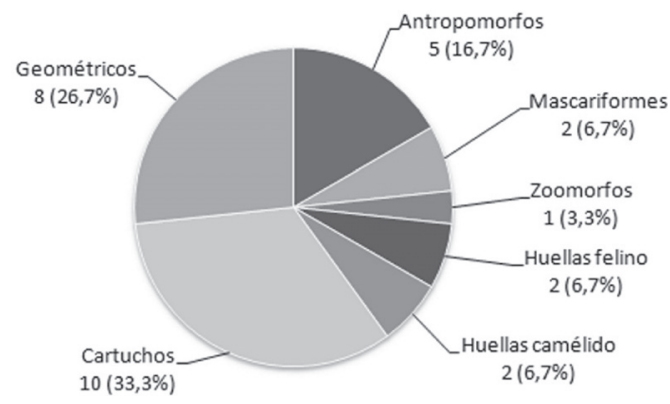

Figura 8: Cantidad de motivos por tipo para el periodo Formativo (momento B2) de la UT E1.

Figure 8: Number of Formative motifs (moment B2) considering their morphological type.

\section{Momento $C$}

El momento C, al que asignamos al período Tardío, presenta 81 representaciones que conforman 37 motivos. Como se puede ver en la figura 9 , existe una marcada tendencia al uso de los espacios libres del soporte, tal como sucediera en el momento anterior B2. Nuevamente, la técnica de ejecución empleada para todas las representaciones de este momento es el grabado.

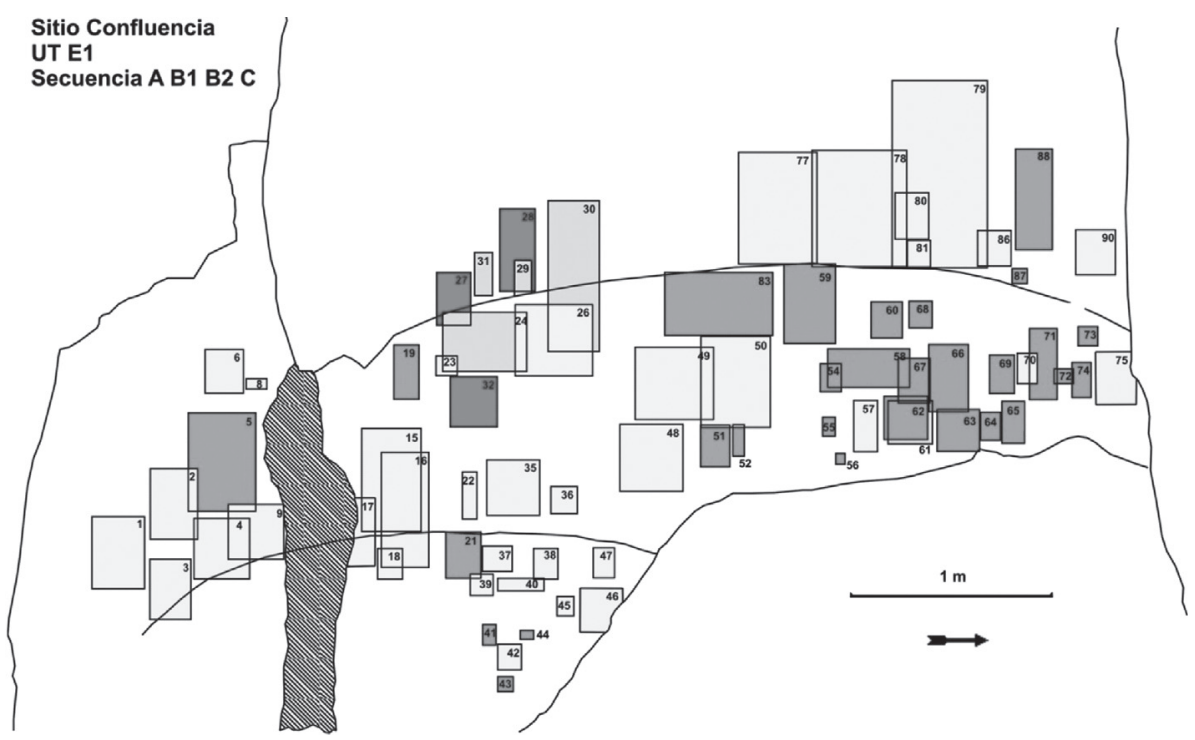

Figura 9: Distribución de los motivos del periodo Tardio, momento $C$.

Figure 9: Distribution of Late period motifs, moment $C$. 
La distribución por tipo de motivo del momento $\mathrm{C}$ presenta las dos características principales que se observa en numerosos sitios con arte rupestre de las áreas valliserrana y puneña del NOA; esto es, a) un alto porcentaje de motivos figurativos respecto de los no figurativos, y b) una mayor presencia de motivos de camélidos en relación al resto del conjunto (Figura 10).

Respecto a la figura del camélido, siguiendo la clasificación de Aschero (2000), pudimos registrar diversos patrones de diseño para la misma, siendo el más frecuente el patrón H0 (y variantes) y un caso comparable al H2, característicos en las modalidades estilísticas Confluencia y Derrumbes -1000 a 1500 d.C.- (Martel 2010). Respecto al H2, Aschero (2000) lo denomina como patrón Inca Cueva, relacionándolo con el patrón E (Berenguer 1994) o Grupo A (Berenguer et al. 2007), definido para el Alto Loa, norte de Chile. Ambos investigadores coinciden en que este patrón es el de mayor presencia en el área centro sur andina, y con una asignación cronológica correspondiente al período Tardío.

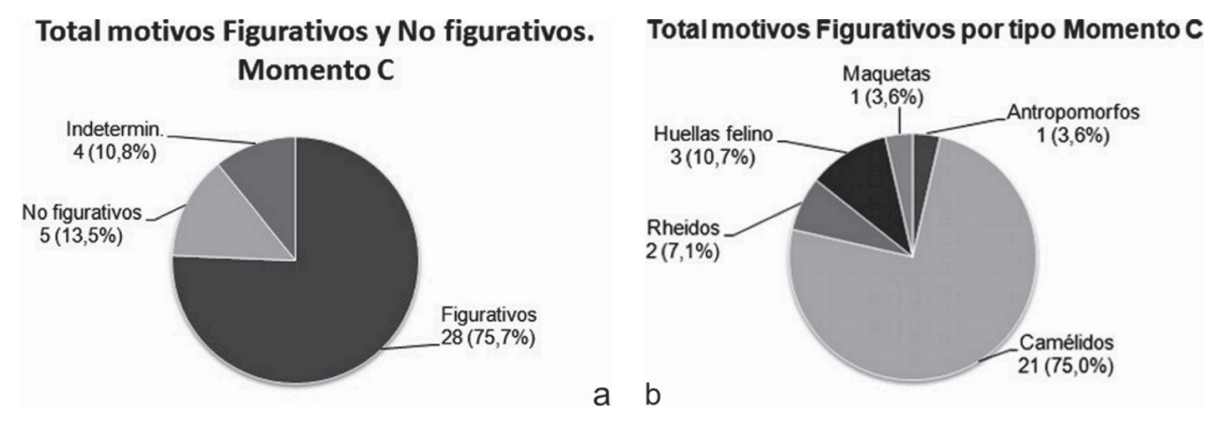

Figura 10: Distribución cuantitativa y porcentual de los motivos del periodo Tardio (momento C), según criterios (a) morfológico y (b) tipológico.

Figure 10: Quantitative distribution and percentage of Late period motifs (moment C), according to (a) morphological and (b) typological criteria.

Otros motivos que nos aportan elementos diagnósticos para la asignación tardía de las representaciones del momento C, son las figuras de aves que, en este caso, comprenden dos motivos de rheídos (suris); uno de ellos (mot. $n^{\circ} 26$ ) se encuentra completo y, en el otro (mot. no 49), por la erosión del soporte, sólo se pueden apreciar la emplumadura, el cuerpo y las patas. La figura del suri tiene una significativa presencia en la iconografía tardía del Valle de Yocavil, sobre todo en la cerámica santamariana (Tarragó 2000), como así también en diversos sitios con arte rupestre tardío del NOA (Podestá et al. 2005). De las diversas formas de representar al suri, aquella 
donde se observa al ave en actitud dinámica con las alas desplegadas, es tal vez la más característica dentro del repertorio; tal es el caso de la UT E1.

Más allá de las características estilísticas, estos motivos presentan otros elementos que nos llevan a pensar en su factura tardía. En primer lugar, los surcos que representan las plumas del mot. no 26 , se superponen a la figura de un camélido (mot. no 24) del momento B1, con pátina fuerte, asignado a la mencionada modalidad estilística Rio Punilla. En segundo lugar, la pátina que presentan los surcos que componen a los dos suris, es débil; correspondiéndose con la tonalidad general de la pátina de los demás motivos de este momento C.

El resto de los motivos de este momento no presentan iguales características diagnósticas, como en el caso de los motivos geométricos y huellas de felino, ya que su ocurrencia ha sido registrada en conjuntos rupestres asignados a periodos anteriores. Sin embargo, sí suponemos una posible factura tardía para la maqueta combinada (mot. no 15) ya que, siguiendo a Aschero et al. (2009), este tipo de representaciones en ANS suelen estar asociadas a motivos adscriptos al período Tardío. Ahora bien, el motivo $\mathrm{n}^{\mathrm{o}} 16$, un conjunto de cinco huellas de felino, fue ejecutado sobre un sector del surco principal de la maqueta, permitiéndonos proponer una cronología tardía para el mismo.

Por último, debemos recordar que la gran maqueta combinada, esculpida en relieve sobre la superficie de los bloques que hacen el estrado de la UT E1 (Figura 11), también ha sido asignada al mismo periodo:

"Desde el punto de vista cronológico la situación cambia para los tipos de maquetas denominados "chacra" y "combinada". A diferencia de la situación anterior, en los casos donde hemos registrado otros motivos asociados directamente a estos tipos (PP4, LT, Cf 1 y CVA), prevalecen las representaciones asignables al periodo Tardio (ca. 1000 a 1480 d.C.), siendo entre éstas la más frecuente la figura del camélido esquemático de dos patas. A esto podemos sumar los casos de Cf 1 y CVA, donde las pátinas débiles son preponderantes, tanto en las representaciones de maquetas como en los camélidos tardios" (Aschero et al. 2009: 216). 


\section{Momento D}

Este momento está representado por sólo cuatro motivos grabados que, desde el análisis del uso del espacio en el soporte, marca un cambio radical respecto de los momentos anteriores (Figura 12). Por su parte, otra de las particularidades de este momento es que las representaciones que lo conforman tienen una amplia distribución regional y remiten, generalmente, a la figura humana. Nos referimos al motivo escutiforme y al antropomorfo T.

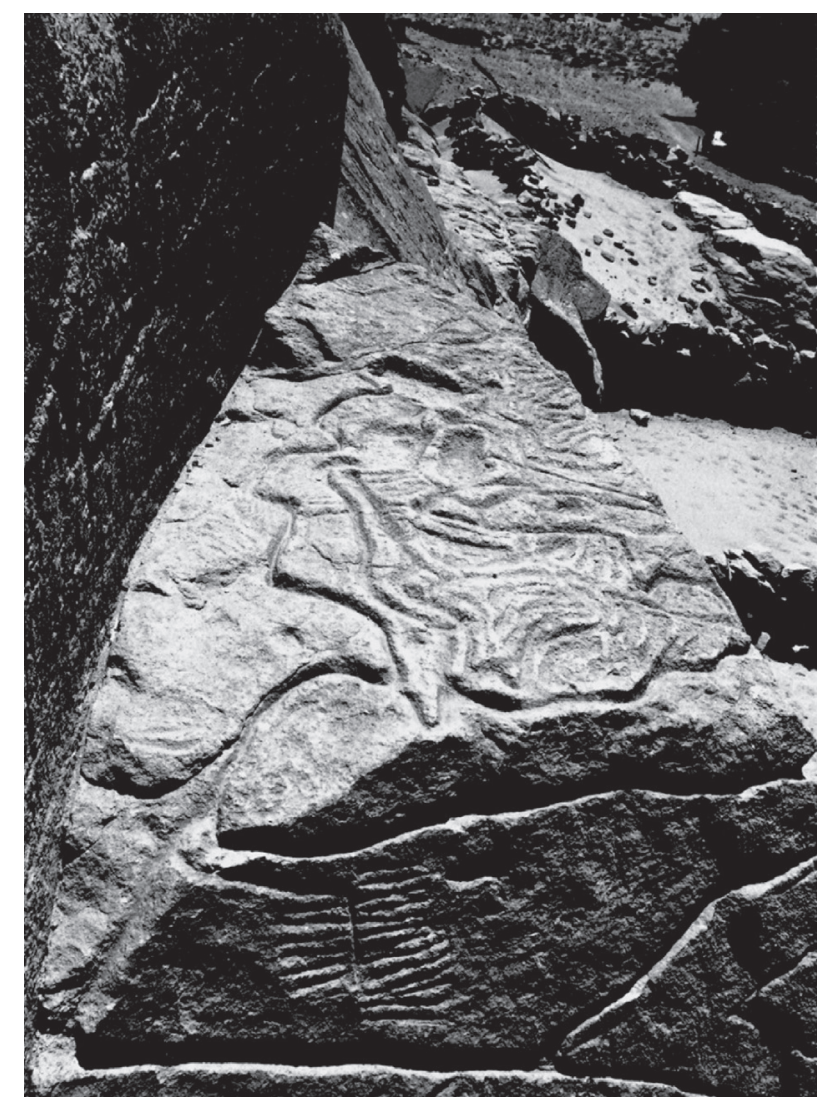

Figura 11: Maqueta combinada (tomada de Aschero et al. 2009). Estrado de la UT E1.

Figure 11: Engraved agricultural scheme (taken from Aschero et al. 2009). Topographic Unit E1. 


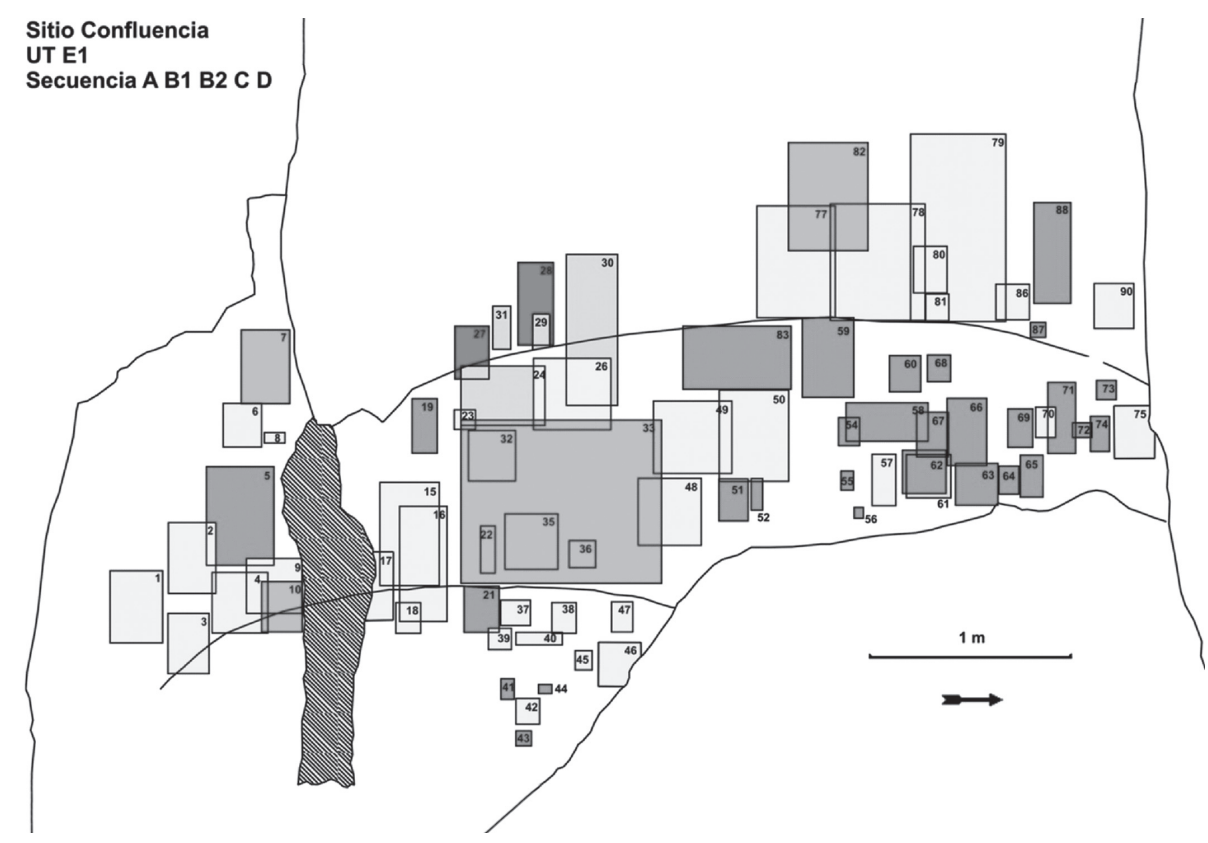

Figura 12: Distribución de los motivos del periodo Tardio final, momento D.

Figure 12: Distribution of late Late period motifs, moment $D$.

Hasta aquí, las representaciones de momentos anteriores (B1, B2 y C), fueron ejecutadas priorizando los espacios libres del soporte, registrándose muy pocas superposiciones respecto de la cantidad de motivos (sobre todo, momentos B2 y C). En este sentido, podemos decir que se dio un cambio en la actitud de los autores respecto a la forma de relacionarse con las representaciones preexistentes. Dos antropomorfos $T$ (mots. no 33 y 82) fueron grabados directamente sobre motivos anteriores (camélidos del patrón tardío H0), con dimensiones y posiciones dentro del panel, que los destacan por sobre el resto del conjunto (Figura 13). En el caso del otro antropomorfo $\mathrm{T}$ (mot. $\mathrm{n}^{\mathrm{o}} 10$ ), presenta un tamaño menor que los otros y una posición en el panel no destacada, sin embargo, se encuentra superpuesto a un camélido del patrón H0. Esto nos lleva a proponer una factura del conjunto en momentos tardíos finales, aunque siguiendo la reciente propuesta de López Campeny y Martel (2010), el análisis estilístico de ciertos atributos de estos motivos permitirá plantear su ejecución en momentos de contacto u ocupación inkaica en la zona. 


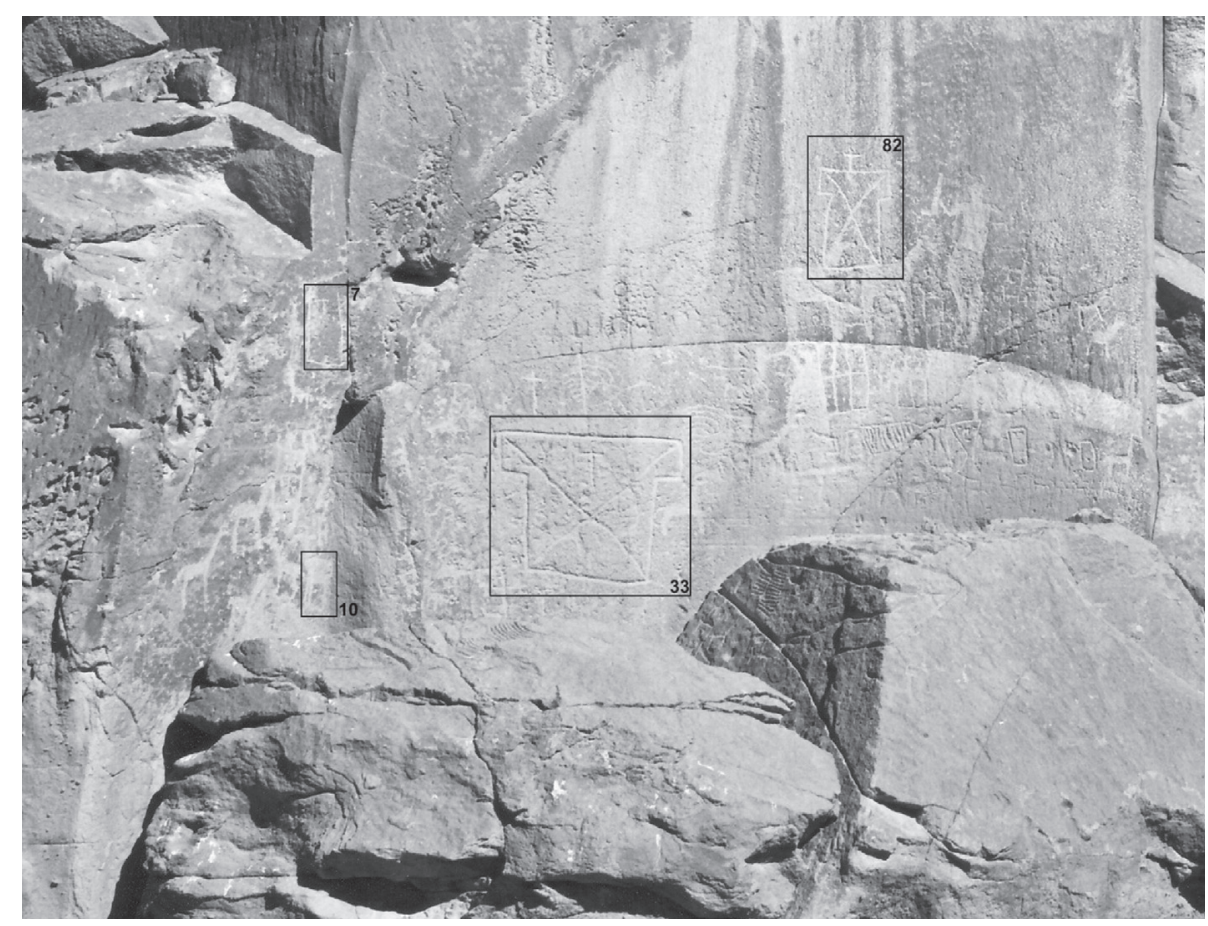

Figura 13: Motivos de antropomorfos Ty escutiforme.

Figure 13: T-anthropomorphous and Shell-like anthropomorphous motifs.

\section{Momento E}

El momento E, se compone exclusivamente de motivos de camélidos aislados (mots. no 11 a 14, 20, 84, 85, 89, 91 a 94, 96, 97) y un motivo de caravana (mot. $\mathrm{n}^{\mathrm{0}} 76$ ), compuesta por ocho camélidos. Todos responden a grabados y fueron ejecutados en espacios libres - pero marginales- del soporte, sin registrar superposiciones con motivos anteriores (Figura 14).

La totalidad de los camélidos $(n=22)$, incluidos los que conforman la caravana, responden al patrón H3, definido por Aschero (2000) para el área circumpuna 5 . Se trata de figuras esquemáticas rectilíneas, en perfil estricto, dos patas y marcado estatismo. Generalmente muestran indicación de una sola oreja -en variadas posiciones- y cola mayormente curvada hacia abajo o recta (Figura 15). Las dimensiones promedio del conjunto son, más bien, pequeñas: $10,60 \mathrm{~cm}$ de altura por $12,40 \mathrm{~cm}$ de ancho, diferenciándose claramente de las dimensiones promedio de los otros patrones. 
Para el establecimiento de la posición cronológica relativa de los camélidos H3, en la secuencia propuesta para la UT E1, posterior a los antropomorfos $\mathrm{T}$ y el escutiforme, nos basamos principalmente en la información que nos brindan las representaciones del sitio La Torre, distante unos $2 \mathrm{~km}$ al SE de Confluencia. Allí, en una de las caras de en un bloque de grandes dimensiones, fueron ejecutadas figuras de escutiformes, antropomorfos $\mathrm{T}$ y camélidos H0. En un momento posterior, y por la acción de procesos naturales ${ }^{6}$, el bloque cambia de posición haciendo que el panel gire $90^{\circ}$. Justamente, después de este cambio de posición, se graban en dicho panel diversas figuras de camélidos H3. Esta diacronía, inferida a partir de las posiciones del bloque, es lo que nos permitió definir la ubicación del momento E en la secuencia.

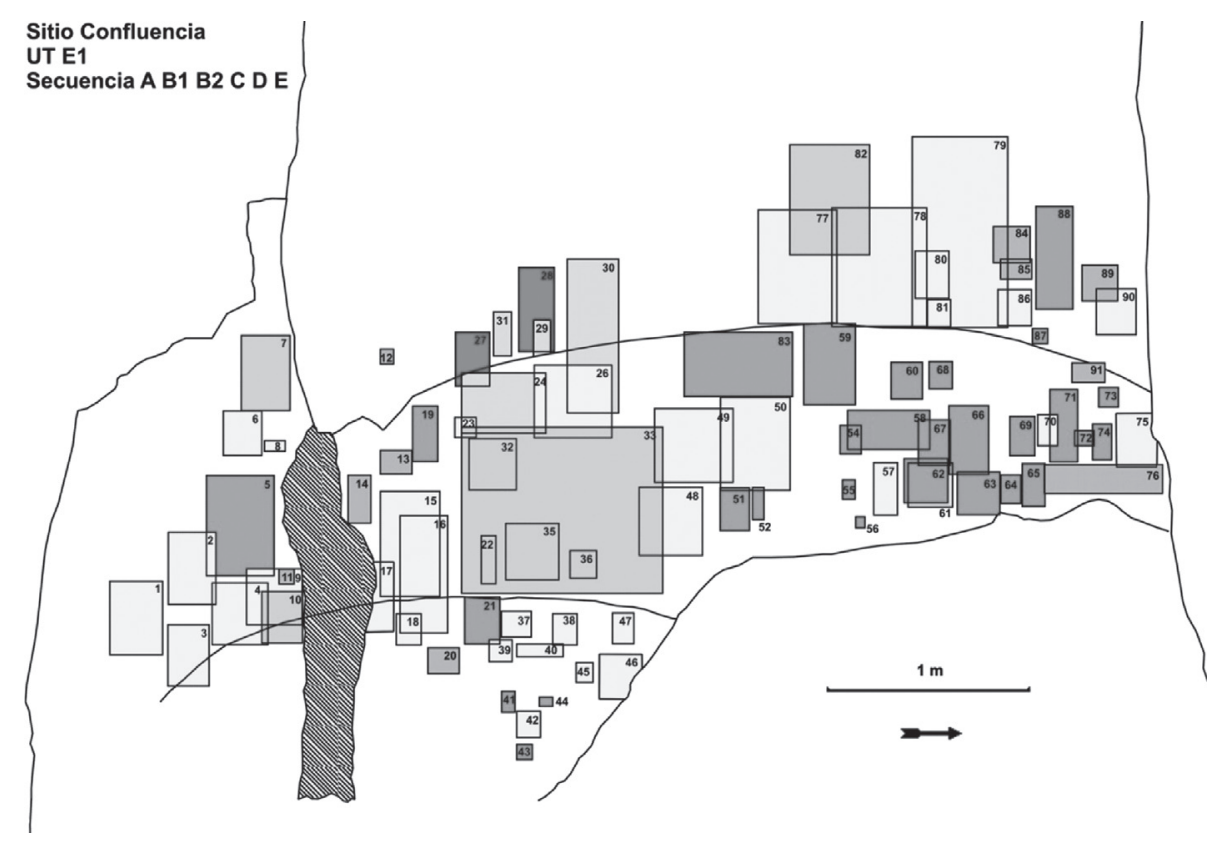

Figura 14: Distribución de los motivos del periodo TardiolInka, momento E.

Figure 14: Distribution of LatelInka period motifs, moment E. 


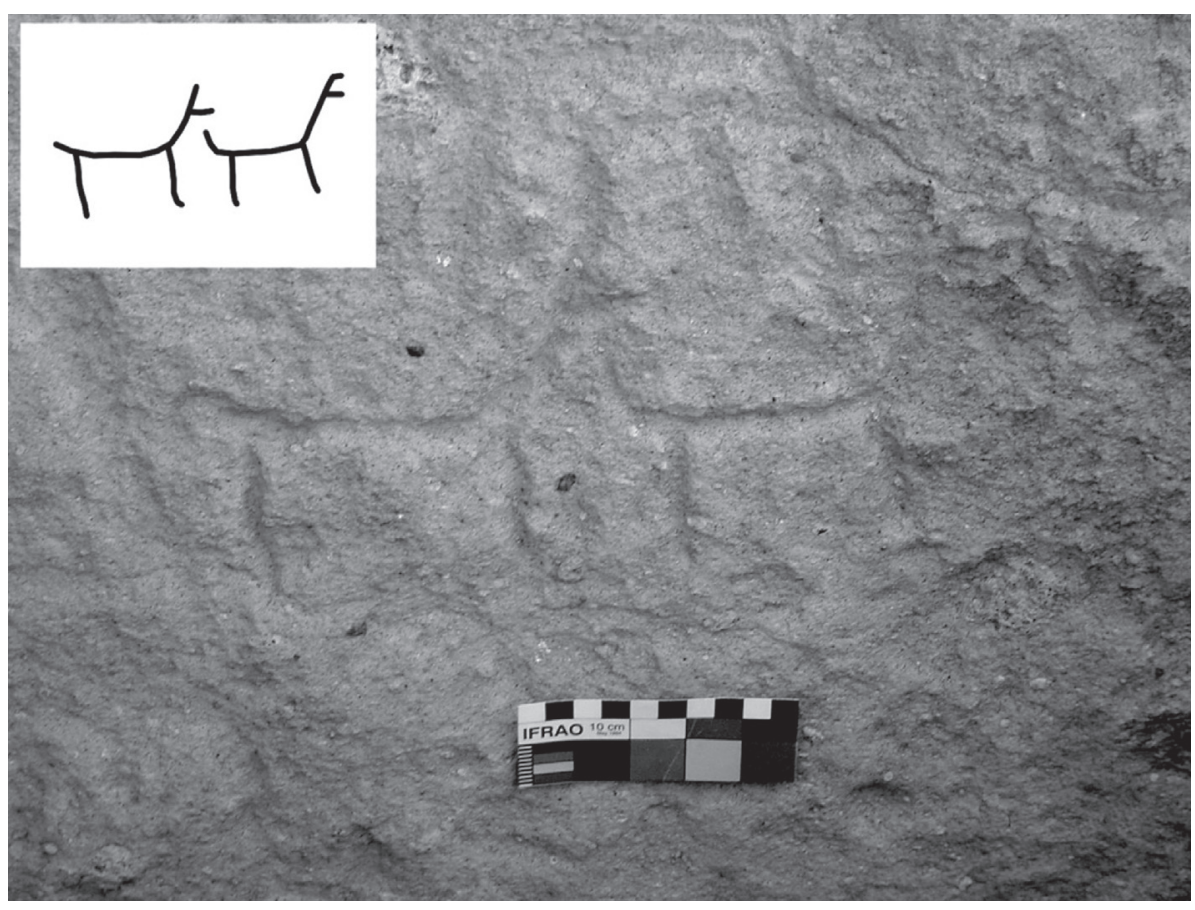

Figura 15: Camélidos esquemáticos rectilineos del patrón H3.

Figure 15: H3 design pattern camelids.

Ahora, haciendo una comparación en sentido contrario, las superposiciones de los antropomorfos T sobre camélidos H0, en la UT E1 de Confluencia, nos lleva proponer que los escutiformes y antropomorfos $\mathrm{T}$ del bloque de La Torre, son posteriores a los camélidos H0 allí presentes?. Por lo tanto, sobre la base de la información recabada a partir del análisis comparativo entre ambos sitios, podemos decir que la producción del arte rupestre tardío se ha dado en tres etapas distintas. La primera, vinculada a camélidos de patrón $\mathrm{H} 0$ y sus variantes, las representaciones de suris y las maquetas tipo chacras y combinadas. La segunda, asociada a los escutiformes y antropomorfos $\mathrm{T} y$, por último, un momento donde el patrón $\mathrm{H} 3$ para la configuración de la figura del camélido parece generalizarse localmente. Pensamos que los camélidos de este patrón podrían ser asignados dentro del lapso de la dominación Inka en la región, sin embargo es preciso revisar las propuestas de otros investigadores sobre la posible cronología de los camélidos esquemáticos lineales.

Para el caso puntual de ANS, Aschero (2000:29) menciona que el patrón $\mathrm{H} 3$, 
"Corresponde a una esquematización geométrica lineal del patrón H2a. Puede aparecer en grabados o pinturas, en diferentes tamaños, incluyendo algunos muy pequeños. En Antofagasta de la Sierra se superponen a los anteriores en el sitio Peñas Coloradas 3 y en Los Pintados de Sapagua, en Azul Pampa [Jujuy], se diferencian de los H2a por un menor grado de pátina".

Si bien Aschero no realiza ninguna observación respecto a una posible ejecución dentro del periodo Inka, si las asocia al momento en que aparecen las representaciones de escutiformes y antropomorfos $\mathrm{T}$, a finales del Tardío. Hernández Llosas (2001) también ubica las figuras de camélidos con diseño más esquemático, hacia el Tardío final, dentro del lapso definido para la Quebrada de Humahuaca como Segmento Temporal 8 (ca. 650 - 550 a.p.), previo a la dominación Inka en la región.

Por otro lado, los diversos estudios realizados en torno a los camélidos esquemáticos lineales en el arte rupestre de la cuenca superior del Río Loa (Alto Loa y Río Salado) en el norte de Chile, tampoco han logrado un acuerdo sobre su asignación cronológica, dándose dos posiciones al respecto. Una, más acorde a las propuestas de Aschero y Hernández Llosas, postula una adscripción cronológica-cultural a grupos agropastoriles del Intermedio Tardío final -o Tardío final, para el NOA- (Berenguer et al. 2007). La segunda posición, asocia la producción de estos camélidos al período Tardío (período Inka para el NOA), dejando abierta la posibilidad de que sus autores hayan pertenecido tanto a comunidades locales como o a grupos vinculados al Inka (Sepúlveda 2008). En nuestro caso particular, nos inclinamos hacia esta segunda posición.

\section{Momento F}

La secuencia planteada para la UT E1, finaliza con el momento F. Dos representaciones grabadas corresponden al mismo; se trata de dos motivos cruciformes (mots. no 25 y 34) que, por la disposición de sus ejes, son comparables a cruces cristianas (Figura 16). La presencia de cruces de este tipo $-\mathrm{u}$ otros símbolos cristianos- en los paneles con arte rupestre prehispánico, es frecuente en el área andina y ha sido vinculada con prácticas coloniales de exorcismo y cristianización. Estas prácticas, realizadas dentro del proceso de extirpación de idolatrías instaurado por la corona en el s.XVI, se llevaron a cabo en los sitios que eran considerados como espacios o escenarios para la realización de cultos paganos (Gallardo et al. 1990). Al respecto, cabe recordar una disposición del virrey Francisco de Toledo, del año 1575 (Castro y Gallardo 1995-1996), donde establece, 
"Ytem, porque de la costumbre envejecida que los indios tienen de pintar idolos y figuras de demonios y animales a quién solian mochar en sus duhos, tianas, vasos, báculos, paredes y edificios, mantas, camisetas, lampas y casi en todas cuantas cosas les son necesarias, parece que en alguna manera conservan su antigua idolatria, proveeréis, en tratando en cada repartimiento, que ningún oficial de aqui adelante labre ni pinte las tales figuras so graves penas, las cuales executaréis en sus personas y bienes, lo contrario haciendo. $Y$ las pinturas y figuras que tuvieren en sus casas y edificios y en los demás instrumentos que buenamente y sin mucho daño se pudiesen quitar que pongan cruces y otras insignias de Xptianos en sus casas y edificios" (el destacado es nuestro).

Por su parte, una de las cruces (mot. no 34) fue grabada, directamente, en el centro del antropomorfo $\mathrm{T}$ de mayor tamaño (mot. no 33), cuyas dimensiones y posición en el panel lo destacan por sobre la mayoría de las representaciones. Por este motivo, asignamos a los motivos de cruces una ejecución posterior al 1575, año de la disposición del Virrey Toledo, y más próxima al 1633, año del -hasta ahora- único documento escrito donde se nombra por primera vez a Antofagasta de la Sierra (García et al. 2000).

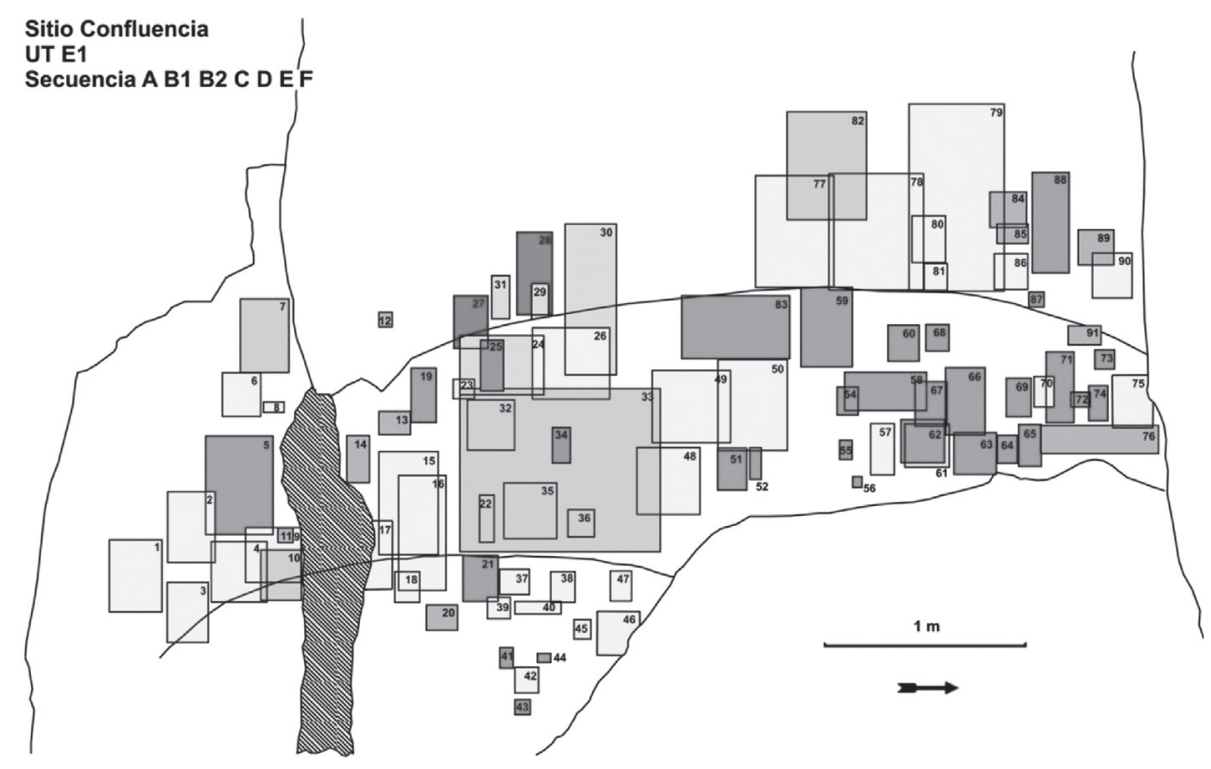

Figura 16: Ubicación de los motivos de cruces cristianas (nos 25 y 34).

Figure 16: Position of Christian crosses motifs (numbers 25 and 34). 


\section{Discusión}

La secuencia propuesta para el conjunto rupestre de la UT E1 de Confluencia nos permite plantear una continuidad en el uso del espacio plástico que se presenta, como dijeran Arenas y Martínez (2009:20), como "un proceso de continuidades con cambios". Resulta sumamente interesante que ese proceso, ese entrelazamiento de agentes, tiempos, trayectorias, cosmovisiones y prácticas, se diera en un punto concreto del espacio, el cual fue progresivamente resignificándose y acumulando fragmentos materiales de una multiplicidad de discursos que -en algunos casos inconsciente y en otros conscientemente- terminaron por conformar la producción rupestre como una práctica y medio para la construcción de memoria social. Es decir, la continuidad de la producción rupestre fue generando, en ese espacio, el argumento y las motivaciones que llevaron a distintos actores a elegir ese mismo panel para la realización de nuevas representaciones.

Teniendo en cuenta nuestro registro, el punto de partida de ese proceso, comprendería a las representaciones del momento A (Arcaico Tardío). Estas fueron producto de ocupaciones tempranas en el sitio y, tal como lo plantea Aschero (1999), podrían estar actuando y significando este espacio como un lugar vinculado a buenos recursos de caza y recolección, siendo posible que las representaciones estén relacionadas a marcas territoriales en la denotación de espacios de retorno previsto. En cuanto al momento B1 (Arcaico Tardío/ Formativo Temprano) las representaciones se ejecutaron muy próximas a las anteriores, aún cuando la disponibilidad de espacio en el soporte era todavía amplia, a partir de esto, podemos destacar que los grabados del momento B1 marcan la continuidad en el uso de un espacio que se resignifica y se adecua a los nuevos requerimientos sociales, económicos y simbólicos que trae aparejado el surgimiento del pastoralismo (Aschero 2007). Por su parte, la proximidad a las representaciones del periodo precedente, concuerda con lo planteado por Aschero (1999), sobre las características principales de la modalidad estilística Río Punilla, es decir, su ocurrencia en los mismos paneles con motivos de modalidades anteriores nos permite proponer una apropiación no sólo de los espacios previamente significados sino, también, de esas figuras preexistentes, a las cuales actualiza -o recontextualiza-en un nuevo escenario social.

Las diferencias que presenta el momento B2 (Formativo) comprenden un considerable aumento de las representaciones y nuevas pautas de elección del espacio plástico. Esto nos brinda la posibilidad, desde el análisis de la relación tema rupestre-emplazamiento, entender mejor la dinámica de un 
paisaje social cuyos espacios productivos, como el de la amplia vega de Confluencia, se ven sujetos a nuevas demarcaciones y negociaciones sobre los derechos de uso y explotación de aquellos recursos, como el agua y las tierras irrigables, que deben readministrarse en función de la intensificación de las actividades agrícolas que caracterizarán el desarrollo del Formativo, fundamentalmente en el fondo de cuenca (Olivera 1992). De allí, la recurrencia de la representación de determinados motivos (p.e. cartuchos y rostros/mascariformes) que, como se ha propuesto en otros trabajos (Aschero et al. 2006 y 2009), aluden a la figura del ancestro y algunos diacríticos sociales como medio para legitimar diversas prácticas. Nuevamente, la no superposición con las manifestaciones rupestres preexistentes y la elección de espacios libres del soporte para la ejecución de nuevas representaciones, destaca esta tendencia de apropiación y resignificación de lo otro, de lo preexistente.

Para el momento C (Tardío), al igual que en los momentos anteriores, se da el uso de los espacios libres dentro del soporte. Esto nos permite sostener que sus autores tuvieron una actitud similar frente a las representaciones precedentes, es decir, los motivos se ejecutaron evitando la superposición con motivos anteriores. Podríamos decir que, las representaciones del momento $\mathrm{C}$, presentan dos grandes temáticas: una pastoril, vinculada a la figura del camélido; y otra agrícola, asociada a las representaciones de maquetas y el manejo simbólico del agua. Si recordamos las características del emplazamiento del sitio, en función de los recursos circundantes, la ocurrencia de estos temas no sorprende. La evidencia obtenida en otros sitios tardíos del fondo de cuenca, como La Alumbrera, Bajo el Coypar I y II, Quebrada de Petra (Olivera y Vigliani 2000-2002, Olivera et al. 2003-2005, Vigliani 2005, Olivera et al. 2008), nos muestra la coexistencia de ambas prácticas socioeconómicas, las que bien pueden haber superpuesto sus espacios de acción a lo largo del ciclo anual productivo. Ahora, si asumimos que el arte rupestre es un potencial producto de la realización de los rituales productivos que acompañaron tales prácticas, la variabilidad temática del conjunto rupestre analizado respondería a la superposición mencionada.

El momento D (Tardío final), evidencia un cambio radical en el uso del espacio en el soporte. En primer lugar, son pocos los motivos representados, ocupan posiciones destacadas en el panel, presentan dimensiones superiores al resto de los motivos más antiguos y se ejecutaron superponiéndose a estos. Sin dudas se trata de un cambio en el modo de representación y una ruptura con lo preexistente, tanto en lo estilístico como en la forma de relacionarse con esos 'otros', esas alteridades, que proponen las manifestaciones previas. 
Esto puede responder a los profundos cambios en la organización política y social de estos grupos que habría llevado a una mayor concentración y burocratización del poder. De este modo, las representaciones del momento $\mathrm{D}$, nos aportan información significativa sobre dos aspectos particulares de la producción de arte rupestre durante el período Tardío. El primero tiene una implicancia cronológica obvia, que su ejecución sobre camélidos tardíos nos está indicando una realización tardía dentro del Tardío; el segundo, que se da en este momento un cambio abrupto en las pautas de producción de las representaciones, tanto a nivel de uso del espacio plástico como a nivel de temas representados. A diferencia de lo que ocurre en los periodos anteriores, no vemos aquí una intención de apropiarse, de incorporar o resignificar lo previo a un nuevo discurso, sino, por el contrario, el nuevo discurso, sus signos, sus referentes y sus significados se imponen a lo que ya existe para apropiarse, ahora sí, de un espacio determinado.

Para el momento E (Tardío/Inka), como en los momentos B2 y C, observamos nuevamente un uso del espacio plástico que no tiende a la superposición sino más bien a la ubicación marginal de lo representado, mientras que en el momento $\mathrm{F}$ (Hispano Indígena) donde dos motivos cruciformes, comparables a las cruces cristianas, son ubicadas en un lugar central dentro del soporte y superpuestas a motivos de momentos anteriores por lo que consideramos que tal superposición no es aleatoria y podría estar en relación a la resignificación de un espacio, cuyas imágenes, habrían sido interpretadas como contrarias u ofensivas al dogma cristiano.

En resumen, la UT E1 del sitio Confluencia, nos muestra una secuencia en la ejecución del arte rupestre que se asocia no sólo a los diferentes períodos arqueológicos, sino también, a los diversos procesos socioculturales que tuvieron lugar en ANS, expresados a través de repertorios iconográficos propios de cada momento. En este sentido, las representaciones del Tardío nos presentan, en una perspectiva diacrónica, dos situaciones contextuales contrastantes. La primera, que corresponde al momento $\mathrm{C}$ de nuestra secuencia, comprende la producción de un arte rupestre que, desde el análisis del uso del soporte, presenta las mismas características observadas para el período anterior (Formativo), es decir, la elección de espacios libres de representaciones preexistentes y un registro muy bajo de superposiciones. Esto, que puede entenderse como una continuidad en la forma de uso del soporte, no se da a nivel de temas representados; en este momento el referente por antonomasia es la llama, y su representación recurrente alude a la importancia de este animal más allá de la esfera de lo económico, habiéndose transformado en uno de los elementos principales de la iconografía de estos 
grupos. Otro de los temas de este momento está dado por las representaciones de maquetas, lo cual nos advierte sobre el impacto que tuvieron las prácticas agrícolas, en general, y el necesario manejo del agua, en particular, en el esquema de representación visual de las comunidades tardías en ANS.

La segunda situación contextual, está dada por la producción de un arte rupestre compuesto, principalmente, por motivos con un alto contenido simbólico -como escutiformes y antropomorfos $\mathrm{T}$ - cuyos referentes corresponderían a personas, o grupos de personas, con cierto poder social o influencia sobre el resto de la comunidad. Por su parte, la ejecución de estas figuras superponiéndose a las demás, está marcando no sólo un cambio en las pautas representacionales del momento, sino también, un cambio en la relación que establecen sus autores con las imágenes preexistentes $\mathrm{y}$, consecuentemente, con el significado que estas tuvieron para sus observadores. Esta situación ha sido definida como imposición iconográfica (Martel y Aschero 2007).

\section{Conclusiones}

En muchas oportunidades, desde nuestra alteridad suponemos a las representaciones y a los motivos rupestres como signos que representan aspectos de la realidad tal como los conocemos y accedemos a ellos en la actualidad, sin embargo es posible que su carácter metafórico y metonímico nos dificulte acceder al concepto o a la idea que le dio origen. Por este motivo, es posible que después de todos los esfuerzos para interpretarlos solo podamos acceder, de manera parcial, a los aspectos significativos de su sintaxis.

Sin embargo, considerando esta situación y retomando lo que planteamos al principio, para comprender la configuración del conjunto rupestre como resultado de un proceso continuo de creación y no como la sumatoria de eventos independientes, es que se planteó un abordaje deconstructivo del mismo, considerando la construcción de ese espacio a través del tiempo, tanto como producto de diferentes procesos sociales como de la variabilidad en el uso del espacio plástico. El arte rupestre puede ser visto, en una perspectiva sincrónica, como la materialización de esas relaciones entre los agentes sociales en un momento determinado y la alteridad que proponen las representaciones preexistentes. Desde un punto de vista diacrónico, éste nos informa sobre los cambios en las percepciones y la forma de relacionarse con esa alteridad. 
Nos enfrentamos a un gran desafío al intentar aproximarnos a las alteridades existentes en diferentes momentos; si pensamos que en cada uno de los momentos mencionados, estos grupos humanos se posicionaron frente a las representaciones precedentes de una manera particular, podemos suponer que ese conocimiento del otro por medio de la materialización de sus ideas y de su manera de percibir el mundo, generó una respuesta que puede ser observada a partir del análisis de las estrategias de ejecución implementadas, referidas no solo a las técnicas utilizadas para su realización, sino al conjunto de acciones y decisiones que llevaron a ejecutar cada representación en determinado lugar y no en otro, con características específicas de cada una.

De este modo, el uso del espacio plástico de la UT E1 de Confluencia, responde a la estructuración de lo social visto como la concatenación de continuidades y rupturas a través de un proceso de larga duración, donde la interacción entre personas, prácticas, espacio y objetos fue construyendo un todo (el conjunto rupestre + el espacio que lo contiene) que difícilmente pueda ser entendido si no es a partir del análisis del modo en que las distintas partes (los diversos momentos de ejecución) se fueron articulando hasta conformarlo. En este sentido, el conjunto rupestre analizado, puede ser definido como memory work, ya que "it refers to the many social practices that create memories, including recalling, reshaping, forgetting, inventing, coordinating, and transmitting" (Mills y Walker 2008: 4).

Para finalizar queremos destacar la importancia que revisten, para el conocimiento de los procesos socioculturales del pasado, estos puntos concretos del espacio. Es allí donde cada nuevo ejecutor fue re-viviendo lo pasado y resignificándolo -a su modo- en una nueva realidad, generando espacios que a lo largo del tiempo fueron aumentando su densidad significativa en la percepción de las sucesivas generaciones y grupos que habitaron una región particular, es decir, constituyéndose a través de la práctica en espacios de memoria.

Agradecimientos: A Carlos Aschero, por el apoyo constante. Al pueblo de Antofagasta de la Sierra. Los trabajos de campo y análisis involucrados en este trabajo fueron llevados a cabo en el marco de la investigación doctoral de uno de los autores y de diversos proyectos dirigidos por el Lic. Carlos Aschero (PIP-CONICET N ${ }^{\text {os }}$ 6398, 3041; FONCyT-PICT N ${ }^{\text {os }} 38127,9888$; CIUNT Nos 26/G205, 26/G404). 
Notas

Para un mayor detalle sobre las modalidades estilísticas del arte rupestre de Antofagasta de la Sierra ver Aschero (1999).

Conceptualmente creemos que es más apropiado plantear una menor variabilidad de temas representados en contraposición al empobrecimiento del vocabulario iconográfico propuesto por Núnez y Dillehay (1995).

Recientemente Montt y Pimentel (2009), sugirieron la denominación de representaciones de hachas personifcadas para este tipo de motivos. Tal denominación, a nuestro juicio, resulta más apropiada ya que resalta la naturaleza icónica de estos motivos.

La denominación de motivo-ícono, tiene el sentido de signo icónico definido por Eco (1981).

Debemos aclarar que lo que en esta investigación se define como patrón $\mathrm{H} 3$, ha sido denominado en el área del Loa como camélidos estilo Quebrada Seca (Gallardo et al. 1999), como Grupo D1 -subestilo del estilo Santa Bárbara I- (Berenguer et al. 2007) y como camélidos Esquema la (Sepúlveda 2008).

Posiblemente la remoción eólica del sustrato arenoso donde apoyaba el bloque, permitió que éste gire -por efecto de gravedad- en sentido de la pendiente.

Para una mayor cantidad de detalles sobre el análisis diacrónico entre las representaciones de los sitios La Torre y Confluencia ver Martel (2010).

\section{BiBLIOGRAFÍA}

Arenas, M. y J. Martínez. 2009. "Construyendo nuevas imágenes sobre los Otros en el arte rupestre andino colonial". Revista Chilena de Antropología Visual 13: 17-36.

Armstrong, F. 2010. "Arte rupestre como memoria. Una aproximación teórica". Resúmenes del VIII Simposio Internacional de Arte Rupestre, pp: 20-24. IAM, FCNeIML, Universidad Nacional de Tucumán.

Aschero, C. 1996. "Arte y Arqueología: una visión desde la Puna argentina". Chungara 28 (1-2): 175-197.

---- 1999. "El Arte rupestre del Desierto Puneño y el Noroeste Argentino". En, Arte Rupestre en los Andes de Capricornio, pp. 97-135. Edición del Museo Chileno de Arte Precolombino y Banco de Santiago. Santiago.

---- 2000. "Figuras humanas, camélidos y espacios en la interacción circumpuneña". En Arte en las Rocas. Arte Rupestre, Menhires y Piedras de Colores en la Argentina, editado por M. Podestá y M. de Hoyos, pp: 1744. Sociedad Argentina de Antropología y Asociación Amigos del INAPL. Buenos Aires.

----- 2006. "De cazadores y pastores. El arte rupestre de la modalidad Río Punilla en Antofagasta de la Sierra y la cuestión de la complejidad en la Puna meridional argentina". En Tramas en la Piedra. Producción y Usos del Arte Rupestre, editado por D. Fiore y M. Podestá, pp: 103-140. Sociedad Argentina de Antropología, AINA, WAC, Buenos Aires.

---- 2007. "Iconos, huancas y complejidad en la Puna sur argentina". En Producción y Circulación Prehispánica de Bienes en el Sur Andino, compilado por A. Nielsen et al., pp: 135-165. Editorial Brujas, Córdoba. 
2010. "Arqueologías de Puna y Patagonia centro - meridional: comentarios generales y aporte al estudio de los cazadores - recolectores puneños en los proyectos dirigidos desde el IAM (1991 - 2009)". En Rastros en el camino... Trayectos e identidades de una institución. Homenaje a los 80 años del IAMUNT, editado por P. Arenas, C. Aschero y C. Taboada, pp: 257-293. EDUNT Editorial, Tucumán.

Aschero, C. y S. Hocsman. 2011. "Arqueología de las ocupaciones cazadorasrecolectoras de fines del Holoceno Medio de Antofagasta de la Sierra (Puna Meridional Argentina)". Chungara 43 (número especial 1): 393-411.

Aschero, C. y A. Martel. 2003-2005. "El arte rupestre de Curuto-5, Antofagasta de la Sierra (Catamarca, Argentina)”. Cuadernos del INAPL 20: 47-72.

Aschero, C., A. Martel y S. López Campeny. 2006. “Tramas en la piedra: rectángulos con diseños geométricos en Antofagasta de la Sierra (Puna meridional argentina)". En Tramas en la Piedra. Producción y Usos del Arte Rupestre, editado por D. Fiore y M. Podestá, pp: 141-156. Sociedad Argentina de Antropología, AINA, WAC, Buenos Aires.

----- 2009. "El sonido del agua... arte rupestre y actividades productivas. El caso de Antofagasta de la Sierra, noroeste argentino". En Crónicas sobre la Piedra. Arte Rupestre de las Américas, editado por M. Sepúlveda, J. Chacama y L. Briones, pp: 257-270. Ediciones Universidad de Tarapacá, Arica.

Berenguer, J. 1994. "Caravaneo prehispánico tardío y cambio cultural en el sistema Santa Bárbara, Alto Loa”. Precirculados del simposio 'El Norte Grande y sus relaciones con el área Centro-Sur andina: Periodos Intermedio Tardio y Tardio', XIII Congreso Nacional de Arqueología Chilena. Universidad de Antofagasta.

Berenguer, J., G. Cabello y D. Artigas. 2007. "Tras la pista del Inca en petroglifos paravecinales al Qhapaqnán en el Alto Loa, norte de Chile". Chungara 39 (1): 29-49.

Castro, V. y F. Gallardo. 1995-1996. "El poder de los gentiles. Arte rupestre en el río Salado (Desierto de Atacama)". Revista Chilena de Antropología 13: 79-98.

Donnan, Ch. 1975. "The thematic approach to Moche Iconography". Journal of Latin American Lore 1 (2): 147-162.

Eco, U. 1981. La Estructura Ausente. Introducción a la Semiótica (2a edición). Editorial Lumen, Barcelona.

Elías, A. 2007. "Tecnología lítica en las sociedades tardías de Antofagasta de la Sierra (Puna Meridional Argentina)”. Estudios Atacameños 33: 59-85. 
Escola, P. 2000. Tecnología Litica y Sociedades Agropastoriles Tempranas. Tesis para optar al grado de Doctor en Arqueología, Facultad de Filosofía y Letras, Universidad de Buenos Aires. Argentina. Ms.

Fernández Distel, A. 1992. "Investigación sobre el Arte Rupestre HispanoIndígena del N. O. de la República Argentina”. En Contribuciones al Estudio del Arte Rupestre Sudamericano 3, editado por R. Querajazu, pp: 172-198. SIARB, La Paz.

Gallardo, F., V. Castro y P. Miranda. 1990. "Jinetes sagrados en el Desierto de Atacama: un estudio de arte rupestre andino". Boletín del Museo Chileno de Arte Precolombino 4: 27-56.

Gallardo, F., C. Sinclaire y C. Silva. 1999. "Arte rupestre, emplazamiento y paisaje en la cordillera del desierto de Atacama". En, Arte Rupestre en los Andes de Capricornio, pp: 57-96. Edición del Museo Chileno de Arte Precolombino y Banco de Santiago. Santiago.

García, S., D. Rolandi y D. Olivera. 2000. Puna e Historia. Antofagasta de la Sierra, Catamarca. Asociación Amigos del Instituto Nacional de Antropología, Buenos Aires.

Gosden, C. 1994. Social Being and Time. Blackwell, Oxford.

Hernández Llosas, M. 2001. "Tres momentos, tres contextos, un lugar: Variaciones temporales y contextuales en el arte rupestre de la Quebrada de Humahuaca, Jujuy, Argentina”. Boletín del Museo Chileno de Arte Precolombino 8: 5-82.

Hocsman, S. 2006. Producción lítica, variabilidad y cambio en Antofagasta de la Sierra -ca. 5500-1500AP-. Tesis para optar al grado de Doctor en Arqueología, Facultad de Ciencias Naturales, Universidad Nacional de La Plata. Argentina. Ms.

López Campeny, S. 2009. Asentamiento, Redes Sociales, Memoria e Identidad. Primer milenio de la Era, Antofagasta de la Sierra, Catamarca. Tesis para optar al grado de Doctor en Arqueología, Facultad de Ciencias Naturales, Universidad Nacional de La Plata. Argentina. Ms.

López Campeny, S. y A. Martel. 2010. “'IConografía textil o el textil como iconografía? La representación de la figura humana en el arte rupestre del Tardío en el noroeste de Argentina”. Resúmenes del VIII Simposio Internacional de Arte Rupestre, pp: 186-190. IAM, FCNeIML, Universidad Nacional de Tucumán.

Magariños de Morentín, J. 2008. La Semiótica de los Bordes. Apuntes de Metodología Semiótica. Editorial Comunic-Arte, Córdoba. 
Martel, A. 2006. "Arte rupestre y espacios productivos en el Formativo: Antofagasta de la Sierra (Puna meridional argentina)". En Tramas en la piedra. Producción y usos del arte rupestre, editado por D. Fiore y M. Podestá, pp: 157-167. Sociedad Argentina de Antropología, AINA, WAC. Buenos Aires.

----- 2010. Arte Rupestre de Pastores y Caravaneros: Estudio Contextual de las Representaciones Rupestres Durante el Periodo Agroalfarero Tardio (900 d.c. - 1480 d.c.) en el Noroeste Argentino. Tesis para optar al grado de Doctor en Arqueología, Facultad de Filosofía y Letras, Universidad de Buenos Aires. Ms.

Martel, A. y C. Aschero. 2007. "Pastores en acción: imposición iconográfica vs. autonomía temática”. En Producción y Circulación Prehispánica de Bienes en el Sur Andino, compilado por A. Nielsen et al., pp: 329-349. Editorial Brujas, Córdoba.

Martel, A. y S. Giraudo. 2011. "Semiótica de la imagen en Arqueología: el caso de los escutiformes”. Cuadernos FHyCS-UNJu 39 (suplemento): 219-220.

Martínez, J. 2005. “Imágenes y soportes andinos coloniales. Notas preliminares”. Revista Chilena de Antropología Visual 5: 113-132.

Mills, B. y W. Walker. 2008. "Memory, materiality and depositional practice". En Memory Work: Archaeologies of Material Practices, editado por B. Mills y W. Walker, pp: 3-24. SAR Press, Santa Fe.

Montt, I. y G. Pimentel. 2009. "Grabados antropomorfos tardíos. El caso de las personificaciones de hachas en San Pedro de Atacama (norte de Chile)". En Crónicas sobre la Piedra. Arte Rupestre de Las Américas, editado por M. Sepúlveda, J. Chacama y L. Briones, pp: 221-233. Ediciones Universidad de Tarapacá, Arica.

Núńez, L. y T. Dillehay. 1995. Movilidad Giratoria, Armonía Social y Desarrollo en los Andes Meridionales: Patrones de tráfico e interacción económica. Universidad Católica del Norte, Antofagasta.

Olivera, D. 1991. "La ocupación inca en la Puna meridional argentina: Departamento de Antofagasta de la Sierra, Catamarca”. Comechingonia 9 (tomo especial): 31-72.

1992. Tecnología y Estrategias de Adaptación en el Formativo (Agroalfarero Temprano) de la Puna Meridional Argentina. Un Caso de Estudio: Antofagasta de la Sierra (Pcia. de Catamarca, R.A.). Tesis para optar al grado de Doctor en Arqueología, Facultad de Ciencias Naturales, Universidad Nacional de La Plata. Ms. 
Olivera, D. y M. Podestá. 1993. "Los recursos del arte: arte rupestre y sistemas de asentamiento- subsistencia formativos en la Puna Meridional Argentina". Arqueología 3: 93-126.

Olivera, D. y S. Vigliani. 2000-2002. "Proceso cultural, uso del espacio y producción agrícola en la Puna meridional argentina". Cuadernos del INAPL 19: 459-481.

Olivera, D., A. Vidal y L. Grana. 2003. "El sitio Cueva Cacao 1A: hallazgos, espacio y procesos de complejidad en la Puna meridional (ca. 3000 AP)". Relaciones de la Sociedad Argentina de Antropología XXVIII: 257-270.

Olivera, D., S. Vigliani, A. Elías, L. Grana y P. Tchilinguirian. 2003-2005. "La ocupación tardío-inka en la Puna meridional: el sitio Campo Cortaderas". Cuadernos del INAPL 20: 257-277.

Olivera, D., A. Elías, P. Salminci, P. Tchilinguirian, L. Grana, J. Grant y P. Miranda. 2008. "Nuevas evidencias del proceso sociocultural en Antofagasta de la Sierra. Informe de campaña año 2007”. La Zaranda de Ideas. Revista de Jóvenes Investigadores en Arqueología 4: 99-119.

Podestá, M. y D. Olivera. 2006. "El contexto ecológico y económico del arte rupestre en la arqueología de la Puna Meridional Argentina”. En Kay Pacha. Cultivating Earth and Water in the Andes, editado por P. Dransart, pp: 137 -149. BAR International Series 1478. Archaeopress, Oxford.

Podestá, M., D. Rolandi y M. Sánchez Proaño. 2005. El Arte Rupestre de Argentina Indigena. Noroeste. Union Académique Internationale y Academia Nacional de Historia. Buenos Aires.

Preucel, R. 2006. Archaeological Semiotics. Blackwell Publishing, Malden.

Raffino, R. y M. Cigliano. 1973. "La Alumbrera: Antofagasta de la Sierra. Un modelo de ecología cultural prehispánica". Relaciones de la Sociedad Argentina de Antropología VII (N. S.): 241-258.

Sepúlveda, M. 2008. "Arte rupestre en tiempos incaicos: nuevos elementos para una vieja discusión". En Lenguajes Visuales de los Incas, editado por P. González y T. Bray, pp: 111-124. BAR International Series 1848. Archaeopress, Oxford.

Tarragó, M. 2000. "Chacras y pukara. Desarrollos sociales tardíos". En Nueva Historia Argentina, Tomo I. Los Pueblos Originarios y la Conquista, pp: 257300. Editorial Sudamericana, Buenos Aires.

Troncoso, A. 2002. "A propósito del arte rupestre". Werken 3: 67-79. 
----- 2005. "Hacia una semiótica del arte rupestre de la cuenca superior del río Aconcagua, Chile central". Chungara 37/1: 21-35.

Vigliani, S. 2004. "Entre intereses estatales y estrategias de control: el paisaje como aproximación teórico-metodológica". Revista Andina 39: 153-178.

---- 2005. "El sitio Bajo del Coypar II: Las evidencias más tempranas (ca. 1000 AP) del proceso agropastoril en la Puna meridional argentina (Antofagasta de la Sierra, Catamarca)". Andes 16: 325-350. 